\title{
Oxide Thermoelectric Materials: A Structure-Property Relationship
}

\author{
ABANTI NAG ${ }^{1,2}$ and V. SHUBHA ${ }^{1}$ \\ 1.-Materials Science Division, CSIR-National Aerospace Laboratories, Bangalore 560017, India. \\ 2.-e-mail: abanti@nal.res.in
}

Recent demand for thermoelectric materials for power harvesting from automobile and industrial waste heat requires oxide materials because of their potential advantages over intermetallic alloys in terms of chemical and thermal stability at high temperatures. Achievement of thermoelectric figure of merit equivalent to unity $(Z T \approx 1)$ for transition-metal oxides necessitates a second look at the fundamental theory on the basis of the structure-property relationship giving rise to electron correlation accompanied by spin fluctuation. Promising transition-metal oxides based on wide-bandgap semiconductors, perovskite and layered oxides have been studied as potential candidate $n$ - and $p$-type materials. This paper reviews the correlation between the crystal structure and thermoelectric properties of transition-metal oxides. The crystal-site-dependent electronic configuration and spin degeneracy to control the thermopower and electron-phonon interaction leading to polaron hopping to control electrical conductivity is discussed. Crystal structure tailoring leading to phonon scattering at interfaces and nanograin domains to achieve low thermal conductivity is also highlighted.

Key words: Thermoelectric, transition-metal oxides, perovskites, oxychalcogenides, layered cobalt oxides

\begin{tabular}{ll}
$Z$ & \multicolumn{1}{c}{ List of Symbols } \\
$T$ & Figure of merit \\
$Z T$ & Absolute temperature \\
$S$ & Dimensionless figure of merit \\
$\sigma$ & Seebeck coefficient \\
$\kappa$ & Electrical conductivity \\
$\eta$ & Thermal conductivity \\
$T_{\mathrm{h}}$ & Conversion efficiency \\
$T_{\mathrm{c}}$ & Hot-side temperature \\
$T_{\mathrm{m}}$ & Cold-side temperature \\
$k_{\mathrm{B}}$ & Mean temperature \\
$n$ & Boltzmann constant \\
$e$ & Number of charge carriers \\
$\mu_{\mathrm{c}}$ & Electronic charge \\
$H$ & Chemical potential \\
$s$ & Heat transport per particle \\
$E$ & Configurational entropy \\
$V$ & Internal energy \\
$g$ & Internal volume \\
& Electronic degeneracy
\end{tabular}

(Received August 27, 2013; accepted January 9, 2014; published online February 7, 2014)

$\begin{array}{ll}N_{\mathrm{v}} & \text { Number of available sites } \\ \rho & \text { Ratio of charge carriers to sites } \\ U_{0} & \text { On-site Coulomb interaction } \\ v_{\mathrm{ph}} & \text { Optical-phonon frequency } \\ N_{\mathrm{TM}} & \text { Number of transition-metal ions per unit } \\ & \text { volume } \\ R & \text { Average hopping distance } \\ M_{\mathrm{v}} & \text { Ratio of transition-metal ion concentration } \\ \alpha & \text { Electron wavefunction decay constant } \\ W & \text { Activation for conduction } \\ \theta_{\mathrm{D}} & \text { Debye temperature } \\ h & \text { Planck's constant } \\ W_{\mathrm{h}} & \text { Polaron hopping energy } \\ W_{\mathrm{d}} & \text { Disorder energy } \\ N\left(E_{\mathrm{F}}\right) & \text { Density of states at the Fermi level } \\ \kappa_{\mathrm{el}} & \text { Electronic contribution to thermal } \\ & \text { conductivity } \\ \kappa_{\mathrm{lattice}} & \text { Lattice component of thermal conductivity } \\ L & \text { Lorenz factor } \\ C_{\mathrm{V}} & \text { Specific heat per unit volume } \\ v_{\mathrm{s}} & \text { Velocity of sound } \\ \tau & \text { Phonon relaxation time } \\ l_{\mathrm{ph}} & \text { Phonon mean free path } \\ & \end{array}$


$R_{\mathrm{O}} \quad$ Radius of oxygen

$R_{\mathrm{A}} \quad$ Radius of A cation

$R_{\mathrm{B}} \quad$ Radius of B cation

$t \quad$ Tolerance factor

$m^{*} \quad$ Effective mass

\section{INTRODUCTION}

In the recent past, it was realized that there is an urgent requirement for alternative and sustainable energy sources as well as different types of energy conversion technology due to the scarcity of fossil fuels. ${ }^{1-3}$ To arrest the adverse effects of global warming and consequent climate change, green and renewable energy sources such as solar, wind, hydropower, biomass or thermal energy should be taken into consideration. Current research interest focuses on developing functional materials followed by their application in innovative technologies such as fuel cells to convert chemical energy to electricity, photovoltaic cells to convert solar energy (sunlight) to electricity, or thermoelectric generators to enable direct conversion of heat energy to electrical energy. Among the above energy conversion technologies, thermoelectricity has received a resurgence of attention as a large part of the world's overall energy resources such as solar radiation, geothermal heat, and industrial and automobile exhaust are discharged as waste heat into the environment without practical application. Although waste heat can be used as thermal energy for other processes, storage and transfer of heat energy is a Herculean task, while electricity is useful and convenient for many purposes. Thermoelectric energy conversion has therefore received renewed attention, being based on a class of materials known as thermoelectric materials that can recover waste heat and convert it into electrical power. ${ }^{4,5}$ In contrast to other energy conversion technologies, thermoelectric power generation has many desirable properties, such as no moving parts, simple configuration, maintenance-free operation for thousands of hours, adaptability for any temperature range, no scaling effect from milliwatt to kilowatt ranges, etc., to make potential contributions towards reducing greenhouse-gas emissions and providing a cleaner form of energy. ${ }^{6}$

Thermoelectric power generation devices consist of alternate $p$ - and $n$-type thermoelements connected electrically in series and thermally in parallel. In 1821, Seebeck ${ }^{7}$ discovered that a circuit made from two dissimilar metals with the junctions maintained at different temperatures generated an electric voltage (the Seebeck effect). In 1910, Altenkirch $^{8}$ described for the first time the maximum efficiency of a thermoelectric generator and performance of a cooler, which later helped develop the dimensionless figure of merit, $Z T=S^{2} \sigma T \kappa^{-1}$, where $Z$ and $T$ are the figure of merit and the absolute temperature, respectively. To realize efficient thermoelectric energy conversion, the thermoelectric materials should have low thermal conductivity $(\kappa)$, high electrical conductivity $(\sigma)$, and large Seebeck coefficient $(S) .{ }^{9}$ The low $\kappa$ is necessary to introduce a large temperature gradient between two ends of the material, whereas the high $S$ and $\sigma$ are needed to generate a high voltage per unit temperature gradient and to reduce the internal resistance of the material, respectively. Although there is no upper limit on $Z T$ values, most state-ofthe-art thermoelectric materials have a maximum $Z T$ value of 1 to 2 in their respective temperature range of operation because of the interdependence between $S, \sigma$, and $\kappa$. The conversion efficiency $(\eta)$ of thermoelectric power generation is typically defined as

$$
\eta=\left(\frac{T_{\mathrm{h}}-T_{\mathrm{c}}}{T_{\mathrm{h}}}\right)\left[\frac{\sqrt{1+Z T_{\mathrm{m}}}-1}{\sqrt{1+Z T_{\mathrm{m}}}+\frac{T_{\mathrm{c}}}{T_{\mathrm{h}}}}\right],
$$

where $T_{\mathrm{h}}$ and $T_{\mathrm{c}}$ are the hot- and cold-side temperatures, respectively, $T_{\mathrm{m}}$ is the mean temperature, the first term is the Carnot efficiency, and $Z T_{\mathrm{m}}$ is the figure of merit for the device. ${ }^{10}$ The above equation indicates that the thermoelectric energy conversion is related to the figure of merit of the materials and the temperature gradient $\left(T_{\mathrm{h}}-T_{\mathrm{c}}\right)$ of operation. Therefore, considering $T_{\mathrm{c}}$ as room temperature, the higher the hot-side temperature $\left(T_{\mathrm{h}}\right)$, the greater the thermoelectric conversion efficiency, over and above the $Z T$ values of the materials. $Z T=1$ corresponds to $5 \%$ conversion efficiency at $T_{\mathrm{h}}=400 \mathrm{~K}$ and almost $15 \%$ conversion efficiency at $T_{\mathrm{h}}=900 \mathrm{~K}$ considering $T_{\mathrm{c}}=300 \mathrm{~K}$. This clearly indicates that stability at high operation temperature is equally important as high $Z T$ values of the thermoelectric materials to achieve greater heat to electrical energy conversion efficiency. ${ }^{5}$

In 1949 , Ioffe ${ }^{11}$ developed the principles of thermoelectric conversion that heavily doped semiconductors or semimetals with carrier concentration $n$ on the order of $10^{18} \mathrm{~cm}^{-3}$ to $10^{20} \mathrm{~cm}^{-3}$ and with bandgap of $\sim 10 k_{\mathrm{B}} T$ can be the best thermoelectric materials. The state-of-the-art thermoelectric materials used in commercial applications are in agreement with these guidelines and can be divided into three groups, depending on the temperature range of operation (Fig. 1). For near-room-temperature applications such as refrigeration and waste heat recovery up to $450 \mathrm{~K}, \mathrm{Bi}$-Te-based alloys have been proved to possess the best performance (maximum $Z T \approx 0.8$ to 1.4 ) for both $n$ - and $p$-type thermoelectric systems. ${ }^{12}$ The intermediate-temperature region, i.e., $500 \mathrm{~K}$ to $900 \mathrm{~K}$, is the regime of materials based on group IV tellurides such as $\mathrm{Pb}$-Te-based alloys with maximum $Z T>1.5$ at $800 \mathrm{~K}$ for both $p$ - and $n$-type materials. ${ }^{13,14}$ In the high-temperature region $(>900 \mathrm{~K})$, 


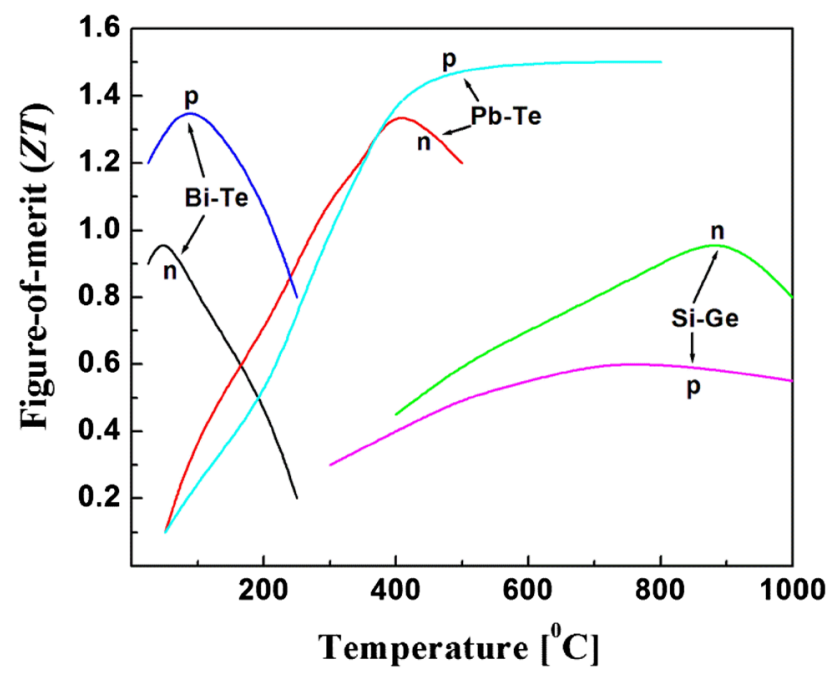

Fig. 1. Thermoelectric figure of merit $(Z T)$ as a function of temperature for state-of-the-art commercial thermoelectric materials.

thermoelectric generators have typically used silicongermanium alloys for both $n$ - and $p$-type elements, though the $Z T$ values of these materials, particularly for the $p$-type Si-Ge alloys, is fairly low because of their relatively high lattice thermal conductivity. ${ }^{5}$

Although the above-mentioned materials remain the cornerstone for commercial applications of thermoelectric generation and refrigeration, the environmental issue of hazardous $\mathrm{Bi}$ and $\mathrm{Pb}$ alloys restricts them from several applications. Further, these compounds are of limited practical use at high temperature $(T \approx 1000 \mathrm{~K})$ because their constituents can easily decompose, vaporize or melt or be oxidized in air at high temperatures. Moreover, employing these heavy metals should be avoided as far as possible, as they are usually toxic, low in abundance as natural resources, and are not environmentally friendly. Compared with the abovementioned thermoelectric alloys, metal oxides are more suitable for high-temperature applications because of their structural and chemical stabilities, oxidation resistance, easy manufacturing, and low cost. $^{15-19}$

\section{PHYSICAL PROPERTIES OF METAL OXIDES}

Metal oxides play a crucial role in a wide range of technological applications including electronics, magnetic devices, optical devices, sensors, actuators, fuel cells, and many more. However, according to Ioffe's theory, metal oxides are considered as poor candidates for thermoelectric applications. Metal oxides are ionic in nature with smaller orbital overlap (narrow band) than covalent intermetallic alloys. This leads to largely polarized metal-oxide bonds, which causes carrier localization with carrier mobility two to three orders of magnitude lower than for the covalent case. On the other hand, the large bonding energies (due to ionic bonds) and the small atomic mass of oxygen result in higher vibrational frequencies of the crystal lattice, yielding high lattice thermal conductivity.

In 1997, Terasaki et al. ${ }^{20}$ reported $\mathrm{Na}_{x} \mathrm{CoO}_{2}$ crystal with large positive Seebeck coefficient $(S \approx 100$ $\left.\mu \mathrm{V} \mathrm{K}^{-1}\right)$ and high electrical conductivity $(\sigma \approx 500$ $\mathrm{S} \mathrm{m}^{-1}$ ). This may result in $Z T$ of 1 , considering the low thermal conductivity $\left(\kappa \approx 4 \mathrm{~W} \mathrm{~m}^{-1} \mathrm{~K}^{-1}\right.$ to $5 \mathrm{~W} \mathrm{~m}^{-1} \mathrm{~K}^{-1}$ ) of $\mathrm{Na}_{x} \mathrm{CoO}_{2}$. This report was a breakthrough for oxide materials as potential thermoelectric candidates, making them competitive with traditional intermetallic thermoelectric materials. During the last decade, oxide thermoelectric materials containing transition-metal oxides with strongly correlated electron systems accompanied by spin fluctuation have attracted much attention as promising candidates and have been extensively investigated.

\section{Seebeck Coefficient of Metal Oxides}

The Seebeck coefficient or thermopower is defined as the difference of electrochemical potential per unit temperature gradient that develops across an electrically isolated sample subjected to a temperature differential. The theory of irreversible thermodynamics ${ }^{21,22}$ relates the thermopower and transport coefficients as follows:

$$
S=-\frac{k_{\mathrm{B}}}{e}\left(\frac{H}{T}-\frac{\mu_{\mathrm{c}}}{T}\right),
$$

where $e$ is the electronic charge, $k_{\mathrm{B}}$ is the Boltzmann constant, $\mu_{\mathrm{c}}$ is the chemical potential, $T$ is the absolute temperature, and $H$ is the heat transport per particle. In the high-temperature limit, heat transport becomes negligibly small as the heat transfer integrals become much lower than $k_{\mathrm{B}} T, H$ can be neglected, and the thermopower becomes proportional to the chemical potential related to the entropy of the system as

$$
S=\frac{\mu_{\mathrm{c}}}{e T}
$$

The thermodynamic identity for chemical potential is

$$
\frac{\mu_{\mathrm{c}}}{T}=\left(\frac{-\partial s}{\partial n}\right)_{E, V},
$$

where $s$ is the configurational entropy, $n$ is the number of charge carriers, and $E$ and $V$ are the internal energy and the internal volume, respectively. The above equation clearly demonstrates that the thermopower can be defined as the entropy per charge carrier in a solid. Therefore, the thermopower can be written as

$$
S=-\frac{1}{e}\left(\frac{\partial s}{\partial n}\right)_{E, V}
$$


However, in strongly correlated systems such as transition-metal oxides, the spin and orbital degrees of freedom of the charge carrier must be considered to evaluate the thermopower. Therefore, for $T \rightarrow \infty$, the entropy can be written as $s=k_{\mathrm{B}} \ln g$, where $g$ is the electronic degeneracy, and the above equation can be rewritten as

$$
S=-\frac{k_{\mathrm{B}}}{e}\left(\frac{\partial \ln g}{\partial n}\right)_{E, V} .
$$

For spinless fermions (Fig. 2A), no two particles can occupy the same site and the degeneracy is

$$
g=\frac{N_{\mathrm{v}} !}{\left(N_{\mathrm{v}}-n\right) ! n !} \text {. }
$$

Using Stirling's approximation and differentiating with respect to $n$,

$$
S(T \rightarrow \infty)=-\frac{k_{\mathrm{B}}}{e} \ln \left(\frac{1-\rho}{\rho}\right),
$$

where $\rho$ is the ratio of charge carriers to sites $(\rho=n /$ $N_{\mathrm{v}} ; n$ is the number of charge carriers and $N_{\mathrm{v}}$ is the number of available sites). This is the generalized Heikes formula. ${ }^{23}$ This situation is physically applicable to a system in enormous magnetic fields or electron-paired with strong binding energy. For fermions with spin $\left(k_{\mathrm{B}} T \gg U_{0}\right.$, where $U_{0}$ is the on-site Coulomb interaction) (Fig. 2B), the electronic degeneracy is expressed as

$$
g=\frac{2 N_{\mathrm{v}} !}{\left(2 N_{\mathrm{v}}-n\right) ! n !} .
$$

The thermopower is expressed as

$$
S(T \rightarrow \infty)=-\frac{k_{\mathrm{B}}}{e} \ln \left(\frac{2-\rho}{\rho}\right) .
$$

For fermions with spin $\left(k_{\mathrm{B}} T \ll U_{0}\right)$ with large electron-electron repulsion (forbidden double occupancy) (Fig. 2C), the electronic degeneracy is expressed as

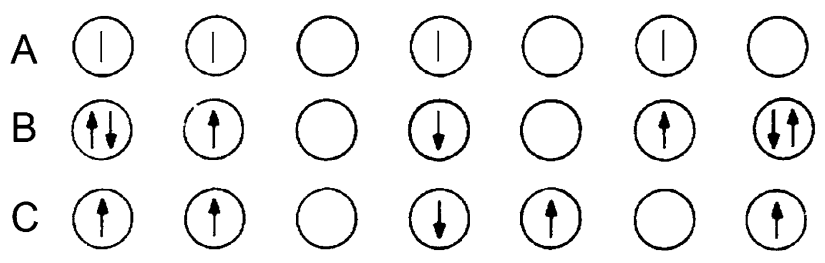

Fig. 2. Possible high-temperature site configuration of $(A)$ spinless fermions, (B) fermions with spin without coulombic interaction, and (C) fermions with spin with large electronic interactions. ${ }^{23}$

$$
g=2^{n} \frac{N_{\mathrm{v}} !}{\left(N_{\mathrm{v}}-n\right) ! n !} .
$$

The thermopower is expressed as

$$
S(T \rightarrow \infty)=-\frac{k_{\mathrm{B}}}{e} \ln \left(2\left[\frac{1-\rho}{\rho}\right]\right) .
$$

For a system in which one ion is present with mixed valency with two different electronic configurations (e.g., $\mathrm{Co}^{3+} / \mathrm{Co}^{4+}$ in $\mathrm{Ca}_{3} \mathrm{Co}_{4} \mathrm{O}_{9}$ or $\mathrm{Mn}^{3+} / \mathrm{Mn}^{4+}$ in doped $\mathrm{CaMnO}_{3}$ ), the electronic degeneracy is calculated considering both electron donor and electron acceptor sites (Table I). Therefore, if $g_{I}$ and $g_{\text {II }}$ are the electronic degeneracies of sites I and II, the thermopower can be expressed as a function of the charge carrier concentration using the modified Heikes formula ${ }^{24}$

$$
S(T \rightarrow \infty)=-\frac{k_{\mathrm{B}}}{e} \ln \left(\frac{g_{\mathrm{I}}}{g_{\mathrm{II}}}\left[\frac{1-\rho}{\rho}\right]\right) .
$$

This equation demonstrates that the magnitude of the carrier concentration $(1-\rho / \rho)$ and the ratio of the electronic degeneracies $\left(g_{\mathrm{I}} / g_{\mathrm{II}}\right)$ of the ions involved play an important role in defining the magnitude and sign of the thermopower for oxide thermoelectric materials. The above formula is applicable to most thermoelectric oxides, including $\mathrm{Na}_{x} \mathrm{CoO}_{2}$ and its derivative structures $\mathrm{La}_{1-x} \mathrm{Sr}_{x} \mathrm{CoO}_{3}$, perovskites and double perovskites, and misfit-layered $\mathrm{Ca}_{3} \mathrm{Co}_{4} \mathrm{O}_{9}$ and its derivative structure $\mathrm{Bi}_{2}(\mathrm{Sr}, \mathrm{Ca}, \mathrm{Ba})_{2} \mathrm{Co}_{2} \mathrm{O}_{9}$.

Figure 3 shows the Seebeck coefficient of $n$-type $\mathrm{Nb}$-doped $\mathrm{CaMnO}_{3}$ and $p$-type $\mathrm{Ca}_{3} \mathrm{Co}_{4} \mathrm{O}_{9}$ synthesized in our laboratory. The negative value of the Seebeck coefficient in the case of $\mathrm{CaMn}_{0.95} \mathrm{Nb}_{0.05} \mathrm{O}_{3}$ indicates $n$-type conduction. The increase in the thermopower with temperature confirms the semiconductor-like behavior. However, the nominal changes in the $S$ value $\left(\sim 30 \mu \mathrm{V} \mathrm{K}^{-1}\right)$ throughout the entire range of temperature indicate that the thermopower is basically determined by the electron concentration (Eq. 5). The experimental thermopower value can be estimated using the Heikes formula (Eq. 9) where $g_{3}$ and $g_{4}$ are the electronic degeneracy of $\mathrm{Mn}^{3+}$ and $\mathrm{Mn}^{4+}$ and $\rho$ is the concentration of $\mathrm{Mn}^{3+}$ at $\mathrm{Mn}$ sites. The theoretical thermopower value for $\mathrm{CaMn}_{0.95} \mathrm{Nb}_{0.05} \mathrm{O}_{3}$ is $S_{\text {theo }}=$ $-178 \mu \mathrm{V} \mathrm{K}^{-1}$ (considering $g_{4} / g_{3}=4 / 10$ and $\rho=0.05$ ) (Table I), which is in good agreement with experimental values for the same composition: $S_{\text {expt }} \approx$ $-170 \mu \mathrm{V} \mathrm{K}^{-1}$ at $750 \mathrm{~K}$.

Similarly, in the case of $\mathrm{Ca}_{3} \mathrm{Co}_{4} \mathrm{O}_{9}$, the positive value of $S$ throughout the entire temperature range indicates $p$-type conduction. As in the case of $\mathrm{CaMnO}_{3}$, the thermopower of $\mathrm{Ca}_{3} \mathrm{Co}_{4} \mathrm{O}_{9}$ can be estimated using the Heikes formula (Eq. 9) where 
Table I. Electronic $(g)$, spin $\left(g_{\text {spin }}\right)$, and orbital $\left(g_{\text {orbital }}\right)$ degeneracy for high-spin (HS), intermediate-spin (IS), and low-spin (LS) $\mathrm{Mn}^{3+}, \mathrm{Mn}^{4+}, \mathrm{Co}^{3+}$, and $\mathrm{Co}^{4+}$ cations in octahedral $\left(O_{\mathrm{h}}\right)$ crystal field

\begin{tabular}{|c|c|c|c|c|}
\hline Cation at $O_{h}$ Site & $d^{n}$ & $g_{\text {spin }}=2 S+1$ & gorbital $^{*}$ & $g=g_{\text {spin }} \times g_{\text {orbital }}$ \\
\hline $\mathrm{Mn}^{3+}(\mathrm{HS})$ & $\mathrm{d}^{4}\left(t_{2 \mathrm{~g}}^{3} e_{\mathrm{g}}^{1}\right)$ & 5 & 2 & 10 \\
\hline $\mathrm{Mn}^{4+}$ & $\mathrm{d}^{3}\left(t_{2 \mathrm{~g}}^{3} e_{\mathrm{g}}^{0}\right)$ & 4 & 1 & 4 \\
\hline $\mathrm{Co}^{3+}(\mathrm{LS})$ & $\mathrm{d}^{6}\left(t_{2 \mathrm{~g}}^{6} e_{\mathrm{g}}^{0}\right)$ & 1 & 1 & 1 \\
\hline $\mathrm{Co}^{3+}(\mathrm{IS})$ & $\mathrm{d}^{6}\left(t_{2 \mathrm{~g}}^{5} e_{\mathrm{g}}^{1}\right)$ & 3 & 6 & 18 \\
\hline $\mathrm{Co}^{3+}(\mathrm{HS})$ & $\mathrm{d}^{6}\left(t_{2 \mathrm{~g}}^{4} e_{\mathrm{g}}^{2}\right)$ & 3 & 5 & 15 \\
\hline $\mathrm{Co}^{4+}(\mathrm{LS})$ & $\mathrm{d}^{5}\left(t_{2 \mathrm{~g}}^{5} e_{\mathrm{g}}^{0}\right)$ & 2 & 3 & 6 \\
\hline $\mathrm{Co}^{4+}(\mathrm{IS})$ & $\mathrm{d}^{5}\left(t_{2 \mathrm{~g}}^{4} e_{\mathrm{g}}^{1}\right)$ & 4 & 6 & 24 \\
\hline $\mathrm{Co}^{4+}(\mathrm{HS})$ & $\mathrm{d}^{5}\left(t_{2 \mathrm{~g}}^{3} e_{\mathrm{g}}^{2}\right)$ & 6 & 1 & 6 \\
\hline
\end{tabular}
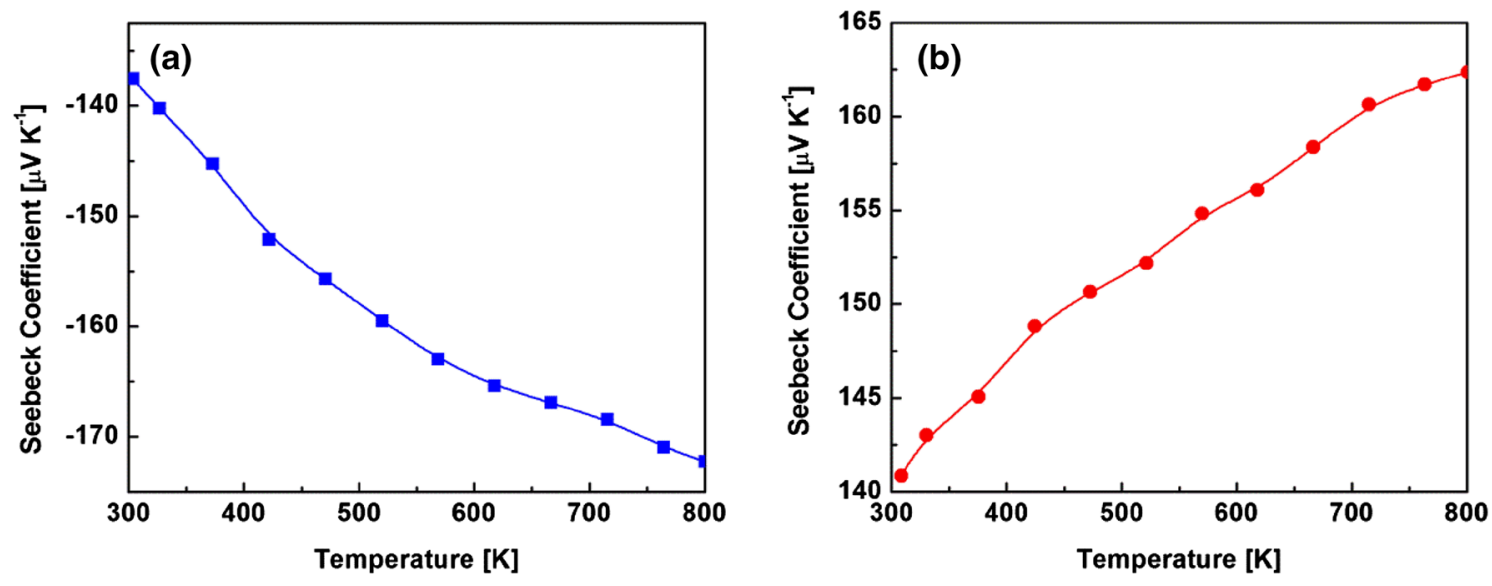

Fig. 3. Seebeck coefficient as a function of temperature for (a) $n$-type $\mathrm{CaMn}_{0.95} \mathrm{Nb}_{0.05} \mathrm{O}_{3}$ and (b) $p$-type $\mathrm{Ca}_{3} \mathrm{Co}_{4} \mathrm{O}_{9}$.

$g_{3}$ and $g_{4}$ are the electronic degeneracy of $\mathrm{Co}^{3+}$ and $\mathrm{Co}^{4+}$ and $\rho$ is the concentration ratio of $\mathrm{Co}^{4+}$ at $\mathrm{Co}$ sites. X-ray absorption study revealed that both $\mathrm{Co}^{3+}$ and $\mathrm{Co}^{4+}$ are in low-spin state in $\mathrm{Ca}_{3} \mathrm{Co}_{4} \mathrm{O}_{9}$, yielding $g_{3} / g_{4}=1 / 6$ (Table I). Considering $g_{3} / g_{4}=$ $1 / 6$, the theoretical thermopower value is estimated to be $S_{\text {theo }}=155 \mu \mathrm{V} \mathrm{K} \mathrm{K}^{-1}$, which is in good agreement with the experimental value for $\mathrm{Ca}_{3} \mathrm{Co}_{4} \mathrm{O}_{9}$ of $S_{\text {expt }} \approx-145 \mu \mathrm{V} \mathrm{K}^{-1}$ at $400 \mathrm{~K}$.

\section{Electrical Conductivity of Metal Oxides}

The electrical conductivity of metal oxides has been explained through the polaron hopping model. In solids, electron-phonon interaction results in the formation of polarons. When the electron-phonon interaction is weak, the overlap of neighboring orbitals is larger, resulting in the creation of large polarons. When the electron-phonon interaction is strong, electrons push negative ions further away, and the overlap of neighboring orbitals becomes narrower until electrons fall into localized states. This phenomenon is defined as a small polaron. ${ }^{25}$
The direct-current (DC) electrical conductivity $(\sigma)$ of oxide materials can be explained on the basis of the polaron hopping conduction theory of Mott ${ }^{26}$ based on the strong electron-phonon (small polaron) coupling approximation. The conductivity in the high-temperature limit $\left(T>\theta_{\mathrm{D}} / 2\right)$ is given by

$$
\sigma \simeq \frac{\sigma_{0}}{T}\left(\exp \frac{W}{k_{\mathrm{B}} T}\right)
$$

where $\sigma_{0}=v_{\mathrm{ph}} N_{\mathrm{TM}} e^{2} R^{2} M_{\mathrm{v}}\left(1-M_{\mathrm{v}}\right) \exp \left(\frac{-2 \alpha R}{k_{\mathrm{p}}}\right), v_{\mathrm{ph}}$ is the optical-phonon frequency $\left(\sim 10^{13} \mathrm{~Hz}\right),{ }_{\mathrm{T}} N_{\mathrm{TM}}$ is the number of transition-metal ions per unit volume, $R$ is the average hopping distance, $M_{\mathrm{v}}$ is the ratio of transition-metal ion concentration in the lowvalence state to the total transition-metal ion concentration, $\alpha$ is the electron wavefunction decay constant of the $3 d$ electron wavefunction, $W$ is the activation for conduction, $T$ is the absolute temperature, and $\theta_{\mathbf{D}}$ is the Debye temperature for the acoustic modes, defined as $\theta_{\mathrm{D}} \approx h v_{\mathrm{ph}} / k_{\mathrm{B}}$, where $h$ is Planck's constant. The tunneling term $\exp (-2 \alpha R)$ reduces to 
unity if the conduction is mainly controlled by the activation energy $W$. This model predicts an appreciable departure from linearity in a $\ln (\sigma)$ versus $1 / T$ plot at low temperature $\left(T<\theta_{\mathrm{D}} / 2\right)$, indicating a decrease in the electrical conductivity with decreasing temperature. Assuming a strong electron-phonon interaction, Austin and Mott ${ }^{27}$ expressed the activation energy for hopping conduction as

$$
W=\left\{\begin{array}{ll}
W_{\mathrm{h}}+\frac{W_{\mathrm{d}}}{2} & \text { for } T>\theta_{\mathrm{D}} / 2 \\
W_{\mathrm{d}} & \text { for } T<\theta_{\mathrm{D}} / 4
\end{array},\right.
$$

where $W_{\mathrm{h}}$ is the polaron hopping energy and $W_{\mathrm{d}}$ is the disorder energy. Both $W_{\mathrm{h}}$ and $W_{\mathrm{d}}$ are dependent on the dielectric constant of the material. ${ }^{28}$

At low temperatures, where the polaron hopping energy $\left(W_{\mathrm{h}}\right)$ is small and the static disorder energy $\left(W_{\mathrm{d}}\right)$ plays a dominant role in the conduction mechanism, Mott ${ }^{29}$ proposed that charge transport may occur beyond nearest neighbors through variable-range hopping. The conductivity for variablerange hopping is given by

$$
\sigma=\sigma_{0} \exp \left[-\left(\frac{T_{0}}{T}\right)^{1 / 4}\right],
$$

where $\sigma_{0}$ and $T_{0}$ are constants and $T_{0}$ is given by

$$
T_{0}=19.4 \alpha^{3} / k N\left(E_{\mathrm{F}}\right)
$$

where $N\left(E_{\mathrm{F}}\right)$ is the density of states at the Fermi level.

A generalized polaron hopping model proposed by Schnakenberg (Eq. 14) indicates that the conductivity at high temperature is dominated by optical multiphonon processes whereas at low temperature the same is governed by a single optical-phonon process. The activation energy in this model decreases with decreasing temperature. ${ }^{30}$

$$
\begin{aligned}
\sigma & \sim \frac{1}{T}\left[\sin h\left(\frac{h v_{0}}{2 k T}\right)\right]^{1 / 2} \exp \left[-\left(\frac{4 W_{\mathrm{h}}}{h v_{0}}\right) \tan h\left(\frac{h v_{0}}{4 k T}\right)\right] \\
& \exp \left(-\frac{W_{\mathrm{d}}}{k T}\right) .
\end{aligned}
$$

Figure 4 shows the electrical conductivity as a function of temperature for $n$-type $\mathrm{CaMn}_{0.95} \mathrm{Nb}_{0.05} \mathrm{O}_{3}$ and $p$-type $\mathrm{Ca}_{3} \mathrm{Co}_{4} \mathrm{O}_{9}$. In both cases, the conductivity increases with temperature, indicating semiconductor-like behavior as evidenced from the thermopower analysis (Fig. 3). The plots of $\ln (\sigma T)$ versus $1 / T$ show a linear fit at high temperature. This confirms that the conduction mechanism can be attributed to small polaron hopping, as expressed by the Mott theory (Eq. 10), between $\mathrm{Mn}^{3+}$ and $\mathrm{Mn}^{4+}$ in $\mathrm{CaMn}_{0.95} \mathrm{Nb}_{0.05} \mathrm{O}_{3}$ or between $\mathrm{Co}^{3+}$ and $\mathrm{Co}^{4+}$ in $\mathrm{Ca}_{3} \mathrm{Co}_{4} \mathrm{O}_{9}$ (Table I).

\section{Thermal Conductivity of Metal Oxides}

In a crystalline solid, heat can be carried by charge carriers, described as the electronic contribution $\kappa_{\mathrm{el}}$, and by lattice vibrations, denoted as the lattice component $\kappa_{\text {lattice }}$. The total thermal conductivity $(\kappa)$ is the overall contribution of the electronic and lattice components and can be expressed as $\kappa=\kappa_{\mathrm{el}}+\kappa_{\text {lattice }}$. The electronic contribution $\left(\kappa_{\mathrm{el}}\right)$ depends on the charge carrier concentration and is related to the electrical conductivity $(\sigma)$ through the Wiedemann-Franz law: $\kappa_{\mathrm{el}}=L \sigma T$, where $L$ is the Lorenz factor on the order of $\frac{3}{2} k_{\mathrm{B}} T$, which is equal to the Lorenz factor $L_{0}=2.45 \times 10^{-8} \mathrm{~W} \Omega \mathrm{K}^{-2}$ for free electrons. The lattice thermal conductivity corresponds to transfer of vibrational energy from one atom to the next, considered as the propagation of a wave. The quantization of vibrational waves is
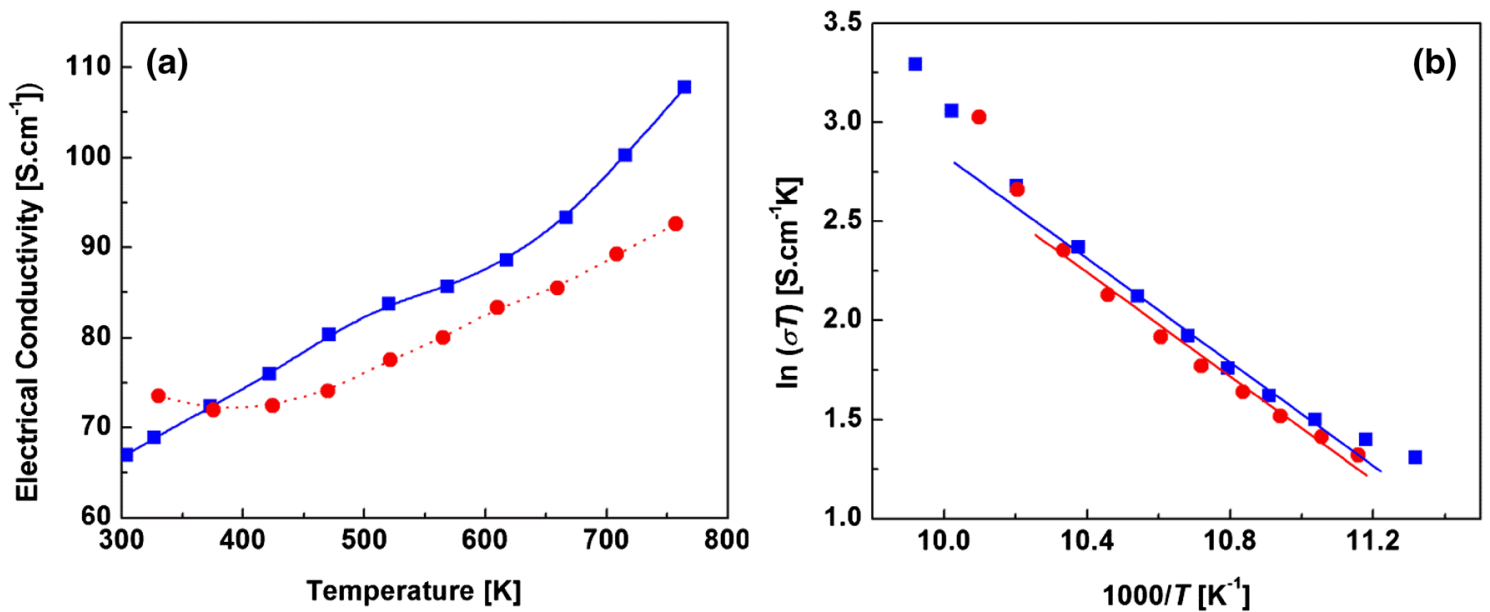

Fig. 4. (a) Temperature dependence of electrical conductivity of $n$-type $\mathrm{CaMn}_{0.95} \mathrm{Nb}_{0.05} \mathrm{O}_{3}$ (blue square) and $p$-type $\mathrm{Ca}_{3} \mathrm{Co}_{4} \mathrm{O}_{9}($ red circle) and (b) In $(\sigma T)$ versus $1000 / T$ for $\mathrm{CaMn}_{0.95} \mathrm{Nb}_{0.05} \mathrm{O}_{3}$ (blue square) and $\mathrm{Ca}_{3} \mathrm{Co}_{4} \mathrm{O}_{9}$ (red circle). The scattered points indicate experimental data, and solid line represents the linear fit. 
called a phonon. Phonons are regarded to be the energy carriers responsible for heat conduction in a lattice. The lattice vibration ${ }^{9}\left(\kappa_{\text {lattice }}\right)$ is independent of the carrier concentration and is observed in all crystalline solids, regardless of whether they are metals, semiconductors, or insulators. The vibration spectrum of a three-dimensional (3D) lattice has three acoustic modes (two transverse and one longitudinal) and ( $3 n-3)$ optical modes (where $n$ is the number of atoms per primitive unit). Optical phonons do not move through the lattice but oscillate back and forth from their standing positions. The acoustic phonons contribute mainly to the lattice thermal conductivity. The lattice thermal conductivity corresponds to the propagation of phonons in the three spatial dimensions through the crystal lattice and is defined by the phonons in the three dimensions as $\kappa_{\text {lattice }}=\frac{1}{3} C_{\mathrm{v}} v_{\mathrm{s}} l_{\mathrm{ph}}=\frac{1}{3} C_{\mathrm{v}} v_{\mathrm{s}}^{2} \tau$, where $C_{\mathrm{V}}$ is the specific heat per unit volume, $\tau$ is the phonon relaxation time, $l_{\mathrm{ph}}$ is the phonon mean free path, and $v_{\mathrm{s}}$ is the velocity of sound, where $v_{\mathrm{s}}=l_{\mathrm{ph}} / \tau$. The lattice thermal conductivity is governed by the combination of phonon-phonon scattering, point defect scattering or (in nanostructured materials) boundary scattering, and is expressed as $\tau^{-1}=\sum_{i} \tau_{i}^{-1}$ or as $\frac{1}{l_{\mathrm{ph}}}=\frac{1}{l_{\text {defect }}}+\frac{1}{l_{\text {boundary }}}+\frac{1}{l_{\text {phoron }}} .{ }^{31} \mathrm{~A}$ limit on the thermal conductivity is set by phonon collisions that do not conserve momentum. The most important processes involve three phonons and can be of two kinds. In normal or $N$-processes, both energy and momentum are conserved, and therefore these do not control the thermal conductivity, rather leading to redistribution of phonons. In Umklapp or $U$-processes, momentum is not conserved, and therefore these directly control the high-temperature thermal conductivity. At high temperatures $\left(T \gg \theta_{\mathrm{D}}\right)$, Umklapp phonon-phonon scattering predominantly contributes towards $\kappa_{\text {lattice }}$ At low temperatures $\left(T \ll \theta_{\mathrm{D}}\right)$, it becomes exceedingly difficult for any U-processes to occur and the thermal conductivity is dominated by boundary and point defect scattering. Boundary scattering in polycrystalline materials depends on the grain sizes and is particularly effective in nanostructured materials such as nanowires, thin films, and nanocomposites. Scattering by point defects arises from both mass and strain contrast within the lattice. Umklapp and point defect scattering target high-frequency phonons, while boundary scattering is often the dominant scattering mechanism at low frequencies. Combining the above scattering mechanisms results in a lattice thermal conductivity which is proportional to $T^{3}$ at low temperatures $\left(T \ll \theta_{\mathrm{D}}\right)$ and varies inversely with temperature $\left(T^{-1}\right)$ at high temperatures $\left(T \gg \theta_{\mathrm{D}}\right)$. However, a detailed theoretical discussion on lattice thermal conductivity lies outside the scope of this paper and is described elaborately in Refs. 9 and 31.

In the case of oxide materials, the major contribution to the total thermal conductivity originates from the lattice. Figure 5 displays the total thermal con- ductivity and the lattice contribution as a function of temperature for both $n$-type $\mathrm{CaMn}_{0.95} \mathrm{Nb}_{0.05} \mathrm{O}_{3}$ and $p$-type $\mathrm{Ca}_{3} \mathrm{Co}_{4} \mathrm{O}_{9}$. The electronic contribution to the thermal conductivity calculated from the Wiedemann-Franz law (mentioned above) is negligible in comparison with the lattice contribution. This figure indicates that the thermal conductivity of both oxides is mostly dominated by the phonon contribution.

Low $\kappa_{\text {lattice }}$ can be obtained by designing many internal interfaces by nanostructuring so that the thermal conductivity can be reduced more than the electrical conductivity due to their different scattering lengths. Nanoengineering techniques enhance phonon scattering through controlling the phonon mean free path by selective scattering of phonons of different wavelength. If the unit cell axis of the oxide is smaller than the mean free path of phonons and larger than the mean free path of electrons or holes, it is possible to reduce $\kappa_{\text {lattice }}$ by boundary scattering. Doping normally affects shortwavelength acoustic phonons. However, mid- to long-wavelength phonons remain largely unaffected and conduct heat in a heavily doped system. In contrast, a nanostructured system can scatter midand long-wavelength phonons and thereby further reduce the lattice thermal conductivity. Nanostructuring can be achieved either by in situ formed inhomogeneities at the nanoscale level (nanoinclusions) driven by phase segregation such as spinodal decomposition and nucleation and growth or by nanocomposite formation. ${ }^{32,33}$

\section{TRANSITION-METAL OXIDES}

Transition-metal oxides with incompletely filled $d$-electrons and narrow energy bands are strongly correlated electron systems where large coulombic interaction yields close correlation of the spin,

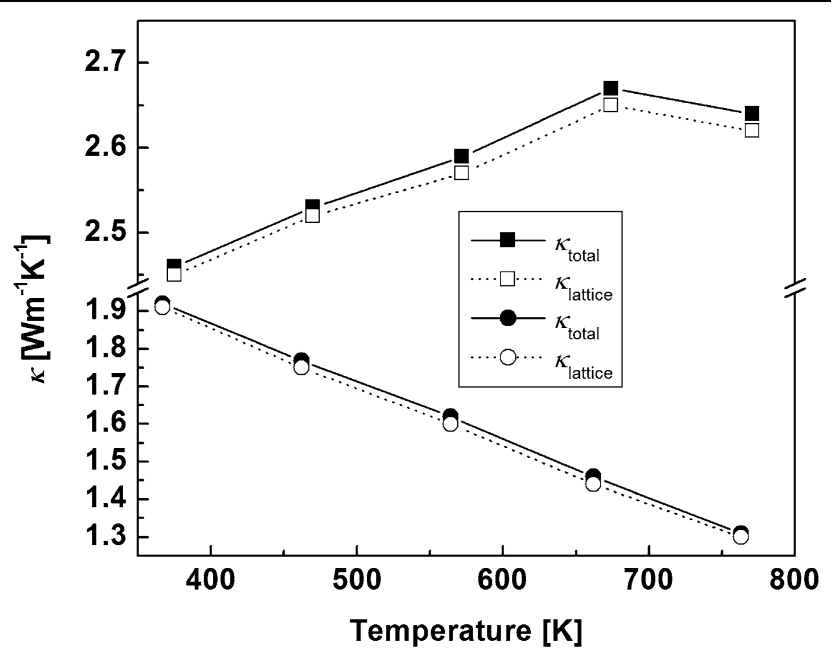

Fig. 5. Temperature dependence of total thermal conductivity $\left(\kappa_{\text {total }}\right)$ and lattice contribution ( $\kappa_{\text {phonon }}$ ) for $n$-type $\mathrm{CaMn}_{0.95} \mathrm{Nb}_{0.05} \mathrm{O}_{3}$ (solid and open squares) and $p$-type $\mathrm{Ca}_{3} \mathrm{Co}_{4} \mathrm{O}_{9}$ (solid and open circles). 
charge, orbital, and lattice degrees of freedom of the electrons. Thermoelectric transition-metal oxides can be categorized into four different classes based on their crystal structure as (i) wide-bandgap semiconductor oxides, (ii) perovskite-based oxides, (iii) layered cobalt oxides, and (iv) layered oxychalcogenides.

\section{Wide-Bandgap Semiconductor Oxides}

Wide-bandgap semiconductors such as $\mathrm{ZnO}$ $(3.37 \mathrm{eV}){ }^{34-37} \mathrm{SnO}_{2}(3.6 \mathrm{eV}),{ }^{38-40}$ and $\mathrm{In}_{2} \mathrm{O}_{3}$ $(3.6 \mathrm{eV})^{41}$ are well-known $n$-type oxide thermoelectric materials. These materials are also known as transparent (bandgap $\sim 1.5 \mathrm{eV}$ to $3.5 \mathrm{eV}$ ) conducting oxides (TCO). They present a broad $s-p$ band in which the electron mobility $(\mu)$ is large, on the order of $10 \mathrm{~cm}^{2} \mathrm{~V}^{-1} \mathrm{~s}^{-1}$ to $100 \mathrm{~cm}^{2} \mathrm{~V}^{-1} \mathrm{~s}^{-1}$, giving rise to high power factors of $10^{-3} \mathrm{~W} \mathrm{~m}^{-1} \mathrm{~K}^{-2}$ to $10^{-4} \mathrm{~W} \mathrm{~m}^{-1} \mathrm{~K}^{-2}$. However, TCO materials exhibit fairly high thermal conductivity $\left(\kappa \approx 5 \mathrm{~W} \mathrm{~m}{ }^{-1} \mathrm{~K}^{-1}\right.$ to $10 \mathrm{~W} \mathrm{~m}{ }^{-1} \mathrm{~K}^{-1}$ ), which in turn results in low figure of merit for these materials. Since the thermal conductivity in oxides is mainly dominated by the lattice contribution, nanostructuring of TCO phases will help in reducing the lattice thermal conductivity through phonon scattering as described in "Thermal Conductivity of Metal Oxides" section. Recently, Ohtaki et al. ${ }^{42-44}$ reported a nanocomposite of $\mathrm{Al} / \mathrm{Ga}$ codoped $\mathrm{ZnO}\left(\mathrm{Zn}_{0.96} \mathrm{Al}_{0.02} \mathrm{Ga}_{0.02} \mathrm{O}\right)$ with $Z T \approx 0.65$ at 1273 K (Fig. 6a). Further, Berardan et al. ${ }^{41}$ reported that addition of $\mathrm{Ge}$ to $\mathrm{In}_{2} \mathrm{O}_{3}$ causes precipitation of fine particles of $\operatorname{In}_{2} \mathrm{Ge}_{2} \mathrm{O}_{7}$ impurity phase, efficiently resulting in a reduced $\kappa$ and thereby high $Z T$ of 0.45 at $1273 \mathrm{~K}$ for the composition $\mathrm{In}_{1.8} \mathrm{Ge}_{0.2} \mathrm{O}_{3}$ (Fig. $6 \mathrm{~b}$ ). Koumoto and coworkers ${ }^{45}$ investigated the thermoelectric properties of the homogeneous compounds $(\mathrm{ZnO})_{m} \mathrm{In}_{2} \mathrm{O}_{3}$ with layered structure and observed that the figure of merit increased with increasing number of $\mathrm{ZnO}$ layers.

\section{Perovskite-Based Oxides}

\section{Simple Perouskite Oxides ${ }^{46}$}

The ideal perovskite oxides are represented by the general formula $\mathrm{ABO}_{3}$, where $\mathrm{A}$ is typically a rareearth, alkaline-earth or alkali cation and $\mathrm{B}$ is the $3 d, 4 d$, or $5 d$ transition metal. The A-site cation is typically larger than the B-site cations. The perovskite structure is described as a framework of a three-dimensional array of corner-shared $\left[\mathrm{BO}_{6}\right]^{8-}$ octahedra forming a large dodecahedral void in which the A cations are situated (Fig. 7a). The dimensions of this framework are determined by the $\mathrm{B}-\mathrm{O}$ distance, which requires $a_{0}=2\left(R_{\mathrm{B}}+R_{\mathrm{O}}\right)$, where $R_{\mathrm{O}}$ is the radius of oxygen and $R_{\mathrm{B}}$ is the radius of $\mathrm{B}$ cation. The cell edge $a_{0}$ determines the size of the dodecahedral void and hence the permissible size of the A cation. Assuming that Goldschmidt's rule is obeyed, i.e., that ions are in contact with each other, it can be seen from the geometry of the unit cell that $\left(R_{\mathrm{A}}+R_{\mathrm{O}}\right)=\frac{\sqrt{2}}{2} a_{0}=\sqrt{2}\left(R_{\mathrm{B}}+R_{\mathrm{O}}\right)$, where $R_{\mathrm{A}}$ is the radius of the $\mathrm{A}$ cation. However, the perovskite structure is stabilized even if this relation is not followed exactly. Goldschmidt defined the tolerance factor $(t)$ as $t=\frac{\left(R_{\mathrm{A}}+R_{\mathrm{O}}\right)}{\sqrt{2}\left(R_{\mathrm{B}}+R_{0}\right)}$. Perovskite-type structures, ideal or distorted, are usually obtained in the range $1.0>t>0.75$; if $t=1$, an ideal perovskite structure is stabilized (e.g., $\mathrm{SrTiO}_{3}$ ). Hexagonal structure is stabilized for $t>1.0$ (e.g., $\left.\mathrm{CaCO}_{3}\right)$. When $t<0.75$, ilmenite-type structures are formed (e.g., $\mathrm{CdTiO}_{3}, \mathrm{FeTiO}_{3}, \mathrm{MgTiO}_{3}$ ). If the relative sizes of the atoms $\mathrm{A}, \mathrm{B}$, and $\mathrm{O}$ are appropriate, an ideal perovskite structure results (e.g., $\mathrm{SrTiO}_{3}$ ); otherwise, distortion in the lattice occurs. The type of distortion depends on (i) rotation or tilting of distortion-free $\mathrm{BO}_{6}$ octahedra, (ii) firstorder Jahn-Teller distortion of $\mathrm{BO}_{6}$ octahedra, and (iii) second-order Jahn-Teller effects on A- and B-cation polyhedra, reflecting mixing
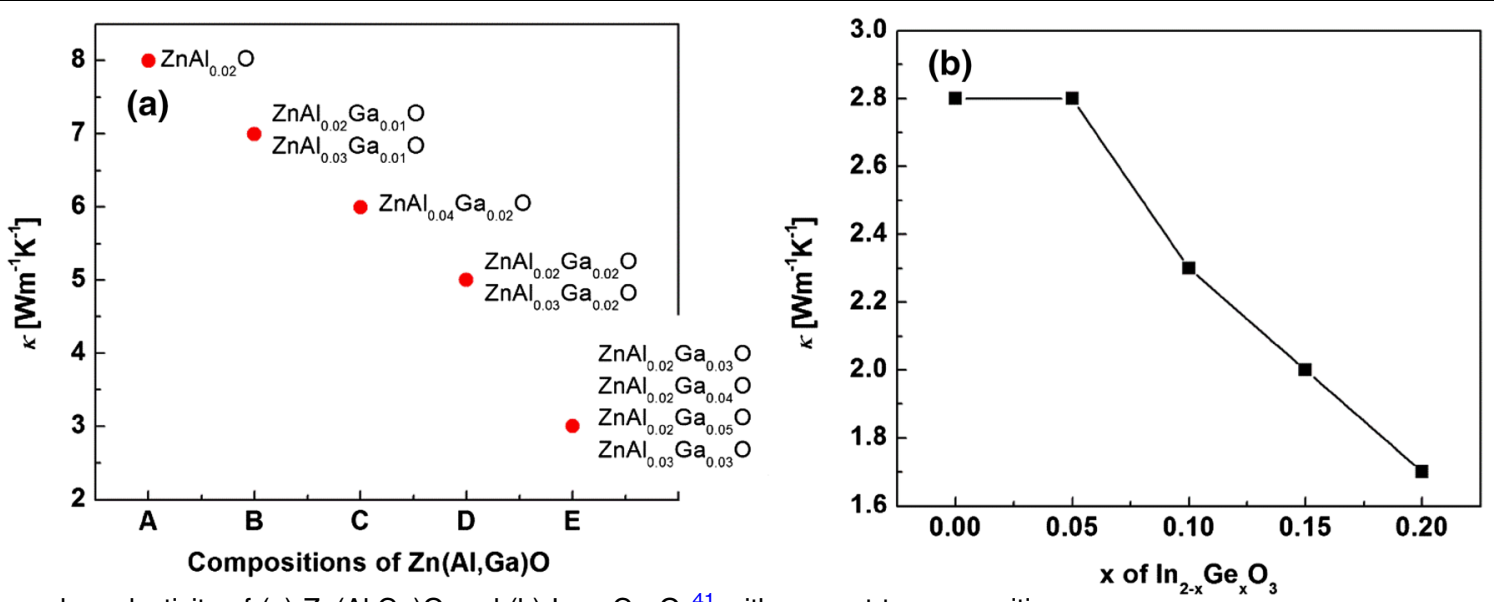

Fig. 6. Thermal conductivity of (a) $\mathrm{Zn}(\mathrm{Al}, \mathrm{Ga}) \mathrm{O}$ and (b) $\mathrm{In}_{2-x} \mathrm{Ge}_{x} \mathrm{O}_{3}{ }^{41}$ with respect to composition. 

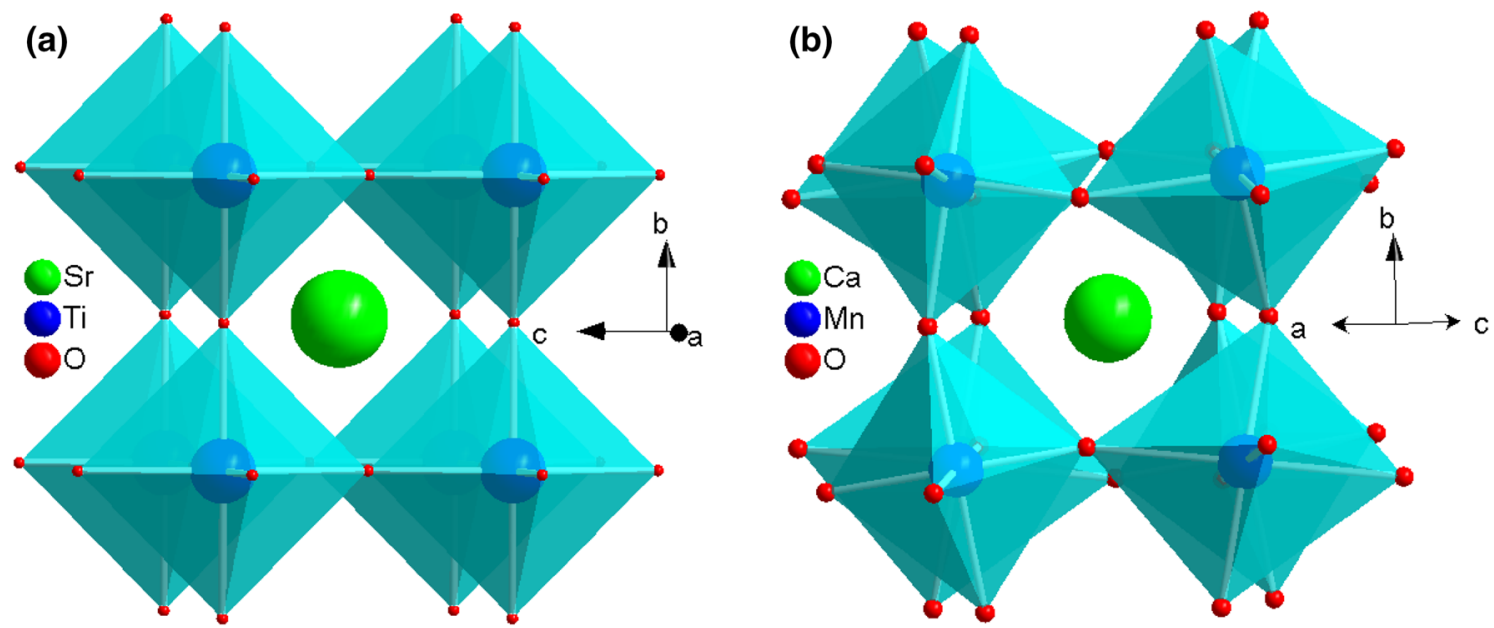

Fig. 7. (a) Ideal perovskite oxide $\mathrm{SrTiO}_{3}(\mathrm{Pm}-3 m)$ and (b) distorted perovskite $\mathrm{CaMnO}_{3}(\mathrm{Pnma}) .^{46}$

of molecular orbitals and/or lone-pair effects. Octahedra tilting is the most common distortion, which occurs due to the small radius of the $A$ cation with respect to its 12 -fold site within the $\mathrm{BO}_{6}$ polyhedral framework. The $\mathrm{BO}_{6}$ octahedra tilt and buckle about pseudocubic axes to accommodate the size of the cuboctahedral void (Fig. 7b). The octahedra tilting results in changes in $\mathrm{A}-\mathrm{O}$ bond length so that they are no longer equal. It also causes changes in the A-site coordination and concomitant reduction of the symmetry from ideal cubic to tetragonal, rhombohedral, orthorhombic, monoclinic or triclinic perovskite. ${ }^{47}$

Perovskite-based oxides are well known for their exotic physical properties such as high-temperature superconductivity, colossal magnetoresistance, ferroelectricity, and thermoelectricity because of their flexible crystal structure. Perovskite-type phases such as cobaltates, titanates, and manganates reveal remarkable thermoelectric properties at high temperatures on doping at the $\mathrm{A}$ and $\mathrm{B}$ cationic sites. Perovskite cobaltates are strongly correlated electron systems with $3 d$ electrons having characteristic degeneracy due to spin and orbital degrees of freedom. In perovskite cobaltates (e.g., $\mathrm{REC} 0^{\mathrm{III}} \mathrm{O}_{3}$ ) where each cobalt ion is surrounded by six oxygens (octahedral crystal field), the competition between the crystal field and Hund's rule coupling is responsible for the degeneracy of the electronic states of $\mathrm{Co}^{3+}\left(\mathrm{Co}^{4+}\right)$ ions in high-spin (HS), intermediate-spin (IS), and low-spin (LS) states with electronic configuration $t_{2 \mathrm{~g}}^{4} e_{\mathrm{g}}^{2}\left(t_{2 \mathrm{e}}^{3} e_{\mathrm{g}}^{2}\right), t_{2 \mathrm{~g}}^{5} e_{\mathrm{g}}^{1}\left(t_{2 \mathrm{~g}}^{4} e_{\mathrm{g}}^{1}\right)$, and $t_{2 \mathrm{~g}}^{6} e_{\mathrm{g}}^{0}\left(t_{2 \mathrm{~g}}^{5} e_{\mathrm{g}}^{0}\right)$, respectively. Different substitutions in such cobaltates may considerably improve their transport properties by changing the oxidation state of cobalt. Substitutions on A-site by divalent cations (e.g., $\mathrm{Sr}^{2+}$ or $\mathrm{Ca}^{2+}$ ) or B-site by divalent cations (e.g., $\mathrm{Ni}^{2+}$ ) generate the formation of holes as charge carriers $\left(\mathrm{Co}^{3+}+\mathrm{h}^{\circ} \rightarrow \mathrm{Co}^{4+}\right)$. Similarly, substitutions on A-site by tetravalent cations (e.g., $\mathrm{Ce}^{4+}$ ) or B-site by tetravalent cations (e.g., $\mathrm{Ti}^{4+}$ ) induce electrons as charge carriers $\left(\mathrm{Co}^{3+}+\mathrm{e}^{\prime} \rightarrow\right.$ $\mathrm{Co}^{2+}$ ). Thus, the sign of the Seebeck coefficient can be adjusted according to the predominance of the charge carriers, i.e., electrons or holes, and thereby $p$ - and $n$-type cobaltates can be designed by suitable substitutions. Among the cobaltates, $\mathrm{LaCoO}_{3}$ exhibits a large positive Seebeck coefficient at room temperature with $S=640 \mu \mathrm{V} \mathrm{K}^{-1}$, which is characteristic for insulating materials. ${ }^{48-51}$ The value of the Seebeck coefficient of $\mathrm{LaCoO}_{3}$ strongly depends on the spin state of the cobalt ions and the temperature. $\mathrm{LaCoO}_{3}$ undergoes two thermally activated spin-state transitions: one at $\sim 100 \mathrm{~K}$ from low-spin to intermediate-spin $\left[t_{2 \mathrm{~g}}^{6} e_{\mathrm{g}}^{0}(\mathrm{LS}) \rightarrow t_{2 \mathrm{~g}}^{5} e_{\mathrm{g}}^{1}(\mathrm{IS})\right]$ state and another at $\sim 500 \mathrm{~K}$ from intermediate-spin to high-spin $\left[t_{2 \mathrm{~g}}^{5} e_{\mathrm{g}}^{1}\right.$ (IS) $\left.\rightarrow t_{2 \mathrm{~g}}^{4} e_{\mathrm{g}}^{2}(\mathrm{HS})\right]$ state, resulting in metallic behavior. Above $500 \mathrm{~K}$, the thermopower converges to a constant value of $S \approx 37 \mu \mathrm{V} \mathrm{K}^{-1}$ irrespective of the nature and level of substitutions, leaving very little scope for application of this material at high temperature. The maximum figure of merit reported for a perovskite cobaltate is $Z T=0.081$ at $660 \mathrm{~K}$ for $\mathrm{DyCo}_{0.95} \mathrm{Ni}_{0.05} \mathrm{O}_{3}$ phase. ${ }^{50}$

Among the perovskite titanates, $\mathrm{SrTiO}_{3}$ and layered titanate phases in the form of single crystals, ${ }^{52,53}$ epitaxial films, ${ }^{54-56}$ and polycrystalline ceramics ${ }^{15,57-63}$ reveal fairly good thermoelectric properties as potential $n$-type thermoelectric materials due to their excellent electronic transport and stability at high temperatures. Polycrystalline $\mathrm{SrTiO}_{3}: \mathrm{Nb}$ showed a highest figure of merit of 0.37 at $1000 \mathrm{~K}$, whereas a thin film of $\mathrm{SrTiO}_{3} / \mathrm{SrTiO}_{3}: \mathrm{Nb}$ superlattice was reported to exhibit a largest estimated $Z T$ of 2.4 at room temperature. Like perovskite cobaltates, perovskite titanates can also be made semiconducting by suitable doping as follows (using Kröger-Vink notation): ${ }^{18}$

A-site doping:

$\mathrm{RE}_{2} \mathrm{O}_{3}+2 \mathrm{BO}_{2} \rightarrow 2 \mathrm{RE}_{\mathrm{A}}^{\bullet}+2 \mathrm{~B}_{\mathrm{B}}^{\times}+2 \mathrm{e}^{\prime}+6 \mathrm{O}_{\mathrm{O}}^{\times}+(1 / 2) \mathrm{O}_{2} \uparrow$

$\mathrm{B}$-site doping:

$2 \mathrm{AO}+\mathrm{Nb}_{2} \mathrm{O}_{5} \rightarrow 2 \mathrm{Nb}_{\mathrm{A}}^{\bullet}+2 \mathrm{~A}_{\mathrm{A}}^{\times}+2 \mathrm{e}^{\prime}+6 \mathrm{O}_{\mathrm{O}}^{\times}+(1 / 2) \mathrm{O}_{2} \uparrow$, 
where $\mathrm{RE}$ denotes a rare-earth element, $\mathrm{A}$ the A-site cation ( $\mathrm{Sr}$ ), and B the B-site cation ( $\mathrm{Ti}$ ), and $\mathrm{e}^{\prime}$ is the excess electrons. The electronic band structure of $\mathrm{SrTiO}_{3}$ is composed of a conduction band formed by $\mathrm{Ti} 3 d$ orbitals consisting of triply degenerate $t_{2 \mathrm{~g}}$ orbitals $\left(3 d_{x y}, 3 d_{y z}\right.$, and $\left.3 d_{x z}\right)$ and a valence band formed by an $\mathrm{O} 2 p$ orbital with a bandgap of $3.2 \mathrm{eV}$. The $d$-band nature of $\mathrm{SrTiO}_{3}$ makes a larger contribution to the effective mass of carrier electrons, resulting in a Seebeck coefficient of $\sim 100 \mu \mathrm{V} \mathrm{K}^{-1}$, even at high carrier concentration. On the other hand, high carrier concentration results in high electrical conductivity, giving rise to high power factor $\left(\mathrm{PF}=3.6 \times 10^{-3} \mathrm{~W} \mathrm{~m}^{-1} \mathrm{~K}^{-2}\right)$ of doped $\mathrm{SrTiO}_{3}$ single crystal comparable to that of conventional $\mathrm{Bi}_{2} \mathrm{Te}_{3}$-based thermoelectric materials. However, as a major drawback of oxide materials, the titanate phases also exhibit high thermal conductivity $\left(\kappa_{300 \mathrm{~K}} \approx 10 \mathrm{~W} \mathrm{~m}^{-1} \mathrm{~K}^{-1}\right)$, due to the dominant contribution from the lattice thermal conductivity, making them unsuitable for practical application. A further disadvantage of titanates is the oxidation of $\mathrm{Ti}^{3+}$ to $\mathrm{Ti}^{4+}$ under air at high temperatures, leading to instability of the phases.

The perovskite manganates undergo two types of structural distortion. One is cooperative rotation of $\mathrm{MnO}_{6}$ octahedra, resulting in orthorhombic $\mathrm{GdFeO}_{3}$-type $\left(a_{\mathrm{c}} \sqrt{2} \times 2 a_{\mathrm{c}} \times a_{\mathrm{c}} \sqrt{2}\right)$ structure. The other one is cooperative Jahn-Teller distortion, i.e. alternate elongation of the $\mathrm{MnO}_{6}$ with $\mathrm{Mn}^{\text {Iil }}$ $\left(e_{\mathrm{g}}^{1} \rightarrow d_{z^{2}}^{1} d_{x^{2}-y^{2}}^{0}\right)$ configuration along one of the axes in the basal plane of the orthorhombic cell. Among the manganates, both $\mathrm{LaMnO}_{3}$ and $\mathrm{CaMnO}_{3}$ exhibit large absolute Seebeck coefficients of $S=450$ $\mu \mathrm{V} \mathrm{K}^{-1}$ and $800 \mu \mathrm{V} \mathrm{K}^{-1}$, respectively, at $300 \mathrm{~K}^{18,64}$ $p$-Type or $n$-type conduction can be accomplished by aliovalent substitutions on either the A- or B-site in both the $\mathrm{LaMnO}_{3}$ and $\mathrm{CaMnO}_{3}$ systems; For example, substitution by divalent cation $\left(\mathrm{Ca}^{2+}\right.$ or $\mathrm{Sr}^{2+}$ ) on $\mathrm{La}^{3+}$ site or divalent transition-metal ion on $\mathrm{Mn}^{3+}$ site of $\mathrm{LaMnO}_{3}$ introduces holes into the system and thereby results in $p$-type conduction.
Similarly, substitution by trivalent rare-earth ${ }^{65-75}$ or $\mathrm{Bi}^{3+}$ ions ${ }^{71}$ on $\mathrm{Ca}^{2+}$ site or pentavalent $\left(\mathrm{Nb}^{5+}, \mathrm{V}^{5+}\right.$, or $\left.\mathrm{W}^{5+}\right)^{76-80}$ or hexavalent $\left(\mathrm{Mo}^{6+}\right)^{81-83}$ substitution on $\mathrm{Mn}^{4+}$ site of $\mathrm{CaMnO}_{3}$ introduces electrons into the system, resulting in $n$-type conduction. The introduction of electron or hole conduction is realized due to the formation of mixed-valence $\mathrm{Mn}^{3+}$ $\left(3 d^{4} \rightarrow t_{2 \mathrm{~g}}^{3} e_{\mathrm{g}}^{1}\right) / \mathrm{Mn}^{4+}\left(3 d^{3} \rightarrow t_{2 \mathrm{~g}}^{3} e_{\mathrm{g}}^{0}\right)$ cations. Among the $\mathrm{CaMnO}_{3}$ compositions, the highest figures of merit are reported for $\mathrm{Yb}$-doped $\mathrm{CaMnO}_{3}$ with $Z T=0.16$ at $1000 \mathrm{~K}$, for Dy-doped $\mathrm{CaMnO}_{3}$ with $Z T=0.2$ at $1273 \mathrm{~K}$, and for $\mathrm{Nb}$-doped $\mathrm{CaMnO}_{3}$ with $Z T>0.3$ at $1073 \mathrm{~K}^{18,78} \mathrm{In}$ our group, we have introduced double substitution at B-sites to understand the role of increasing effective mass on the transport properties of perovskite manganates. ${ }^{84}$ Further, simultaneous substitution at A- and B-sites has been introduced to understand the thermoelectric behavior in highly disordered systems. ${ }^{85}$

\section{Double Perouskite Oxides ${ }^{46}$}

Ordered perovskites are substitutional derivatives of the simple ternary perovskite structure formed when either or both of the A- and B-site cations are replaced by combinations of other cations located at specific crystallographic sites. If cations are ordered at only one site, the compounds are commonly termed double perovskites. The majority of ordered perovskites studied to date are B-site ordered double perovskites. The commonest $\mathrm{B}$-site ordered perovskites have the general formula $\mathrm{A}_{2} \mathrm{~B}^{\prime} \mathrm{B}^{\prime \prime} \mathrm{O}_{6} \quad$ (i.e., $\mathrm{AB}_{0.5}^{\prime} \mathrm{B}_{0.5}^{\prime \prime} \mathrm{O}_{3}$ ) or $\mathrm{A}_{3} \mathrm{~B}^{\prime} \mathrm{B}_{2}^{\prime \prime} \mathrm{O}_{9}$ (i.e., $\mathrm{AB}_{1 / 3}^{\prime} \mathrm{B}_{1 / 3}^{\prime \prime} \mathrm{O}_{3}$ ), where $\mathrm{B}^{\prime}$ and $\mathrm{B}^{\prime \prime}$ are different cations in octahedral coordination situated on crystallographically distinct sites: the ordering styles of these compounds are termed $1: 1$ and 1:2 ordering, respectively (Fig. 8), having the same architecture of 12-coordinate A sites and 6-coordinate B sites with mixed valency. B-site ordering occurs either due to a large size difference between $\mathrm{B}^{\prime}$ and $\mathrm{B}^{\prime \prime}$ ions or when the charge difference is $>2$.
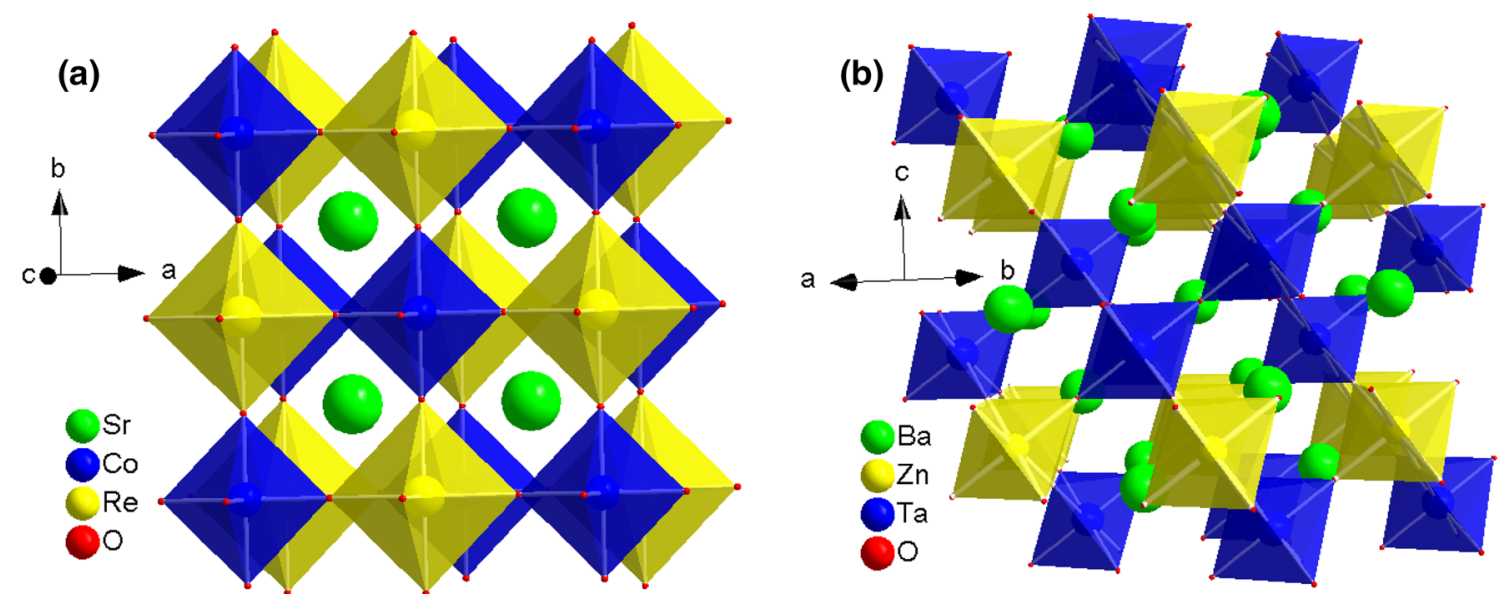

Fig. 8. (a) 1:1 ordered double perovskite $\mathrm{Sr}_{4} \mathrm{Co}_{3} \mathrm{ReO}_{12}(F m-3 m)$ and (b) $1: 2$ ordered double perovskite $\mathrm{Ba}_{3} \mathrm{ZnTa} \mathrm{O}_{9}(P-3 m 1)$. ${ }^{46,86}$ 
Double perovskites are reported to show roomtemperature ferromagnetism and magnetoresistance in $\mathrm{Sr}_{2} \mathrm{FeMoO}_{6}{ }^{87}$ room-temperature magnetodielectricity in $\mathrm{La}_{2} \mathrm{NiMnO}_{6}$ and $\mathrm{La}_{2} \mathrm{CoMnO}_{6},{ }^{88,89}$ and multiferroicity in $\mathrm{Bi}_{2} \mathrm{NiMnO}_{6},{ }^{90}$ to name but a few. Some of the above double perovskites are half-metallic, possessing an unusual electronic structure in which the electrons with one spin have semiconducting properties while the electrons with the opposite spin have metallic properties. Further, in some double perovskites, all the conduction electrons are completely spin-polarized in the vicinity of the Fermi level. The above-mentioned electronic structure could provide promising electrical characteristics, for instance, when one spin has a wide band from a broad orbital, whereas the other spin has a sharp band (density of states) in the neighborhood of the Fermi level. Moreover, strong phonon scattering is expected in ordered-disordered double perovskite systems. ${ }^{91}$ Combining the above two characteristics, i.e., promising electrical conductivity and strong phonon scattering leading to low thermal conductivity, the double perovskite oxides are expected to be good candidates for thermoelectric applications. However, to date, thermoelectric properties have been reported for very few double perovskite oxides. Notable features have been observed for the half-metallic $\mathrm{Sr}_{2-x} \mathrm{M}_{x} \mathrm{FeMoO}_{6}$ $(\mathrm{M}=\mathrm{K}, \mathrm{Ca}, \mathrm{Ba}, \mathrm{La})$ series with thermopower of $S \approx 100 \mu \mathrm{V} \mathrm{K}^{-1}$, electrical conductivity of $\sigma \approx 0.5 \times$ $10^{2} \mathrm{~S} \mathrm{~cm}^{-1}$ to $1.0 \times 10^{2} \mathrm{~S} \mathrm{~cm}^{-1}$, and thermal conductivity as low as $\kappa \approx 0.3 \mathrm{~W} \mathrm{~m}^{-1} \mathrm{~K}^{-1}$ to $0.7 \mathrm{~W} \mathrm{~m}^{-1}$ $\mathrm{K}^{-1}$, giving rise to a figure of merit of $Z T=0.3$ at $1100 \mathrm{~K}^{92,93}$ Recently, Sugahara et al. and Takahashi et al. ${ }^{94,95}$ reported interesting thermoelectric properties for $\mathrm{Sr}_{2-x} \mathrm{RE}_{x} \mathrm{CoTiO}_{6}$ and $\mathrm{Sr}_{2-x} \mathrm{RE}_{x} \mathrm{ErRuO}_{6}$, respectively. This indicates that there is plenty of research interest opening new field to explore double perovskite oxides as high temperature thermoelectric materials.

\section{Layered Perovskite Oxides ${ }^{46}$}

Layered perovskite oxides consist of infinite twodimensional (2D) slabs of $\mathrm{ABO}_{3}$-type structure which are separated by some motif. The general formula for the layers is $\mathrm{A}_{(m-1)} \mathrm{B}_{m} \mathrm{O}_{(3 m+1)}$, where $m$ indicates the size of the 2D slabs, termed as "slabs containing $m$ layers of $\mathrm{BO}_{6}$ octahedra"; i.e., $m=1$ means the slab is one $\mathrm{BO}_{6}$ octahedron thick, $m=2$ means it is two $\mathrm{BO}_{6}$ octahedra thick, etc. The characteristics differentiating layered perovskites are the motif that separates the layers and the offset of the layers from each other, termed the interslab distance. Currently, such layered perovskites are considered to form three groups of homogeneous compounds, which are defined on the basis of the interslab composition (Fig. 9) as follows:

1. The $\mathrm{A}_{m+1} \mathrm{~B}_{m} \mathrm{O}_{3 m+1}$ or $\mathrm{A}_{2}^{\prime}\left[\mathrm{A}_{m-1} \mathrm{~B}_{m} \mathrm{O}_{3 m+1}\right]$ or Ruddlesden-Popper series with layering parallel to [001], e.g., $\mathrm{Sr}_{3} \mathrm{Ti}_{2} \mathrm{O}_{7}(m=2)$ or $\mathrm{Sr}_{4} \mathrm{Ti}_{3} \mathrm{O}_{10}(m=3)$
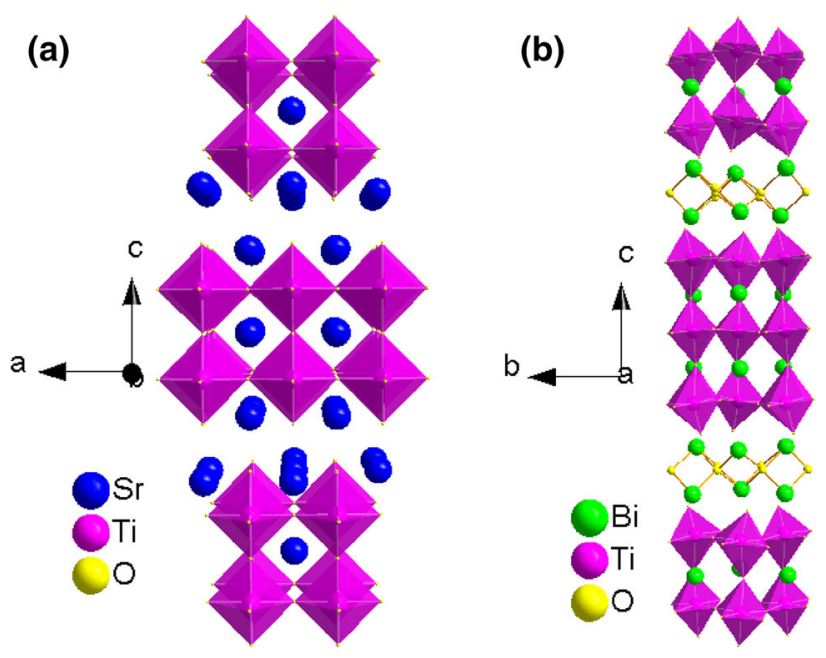

Fig. 9. Layered perovskite of (a) Ruddlesden-Popper $\mathrm{Sr}_{3} \mathrm{Ti}_{2} \mathrm{O}_{7}$ (14/ $\mathrm{mmm}$ ) and (b) Aurivillius $\mathrm{Bi}_{4} \mathrm{Ti}_{3} \mathrm{O}_{12}(B 2 c b) .{ }^{46}$

2. The $\mathrm{A}^{\prime}\left[\mathrm{A}_{m-1} \mathrm{~B}_{m} \mathrm{O}_{3 m+1}\right]$ or Dion-Jacobson series with layering parallel to [001], e.g., $\mathrm{RbCa}_{2} \mathrm{Nb}_{3} \mathrm{O}_{10}$

3. The $\left(\mathrm{Bi}_{2} \mathrm{O}_{2}\right)\left[\mathrm{A}_{m-1} \mathrm{~B}_{m} \mathrm{O}_{3 m+1}\right]$ or Aurivillius phases with layering parallel to [001], e.g., $\mathrm{Bi}_{4} \mathrm{Ti}_{3} \mathrm{O}_{12}$

Ruddlesden-Popper (RP) phases are described by the general formula $\mathrm{SrO}\left(\mathrm{SrTiO}_{3}\right)_{m}(m=$ integer $)$ and are built up with alternately stacked $m$-layer perovskitetype $\mathrm{SrTiO}_{3}$ blocks and one layer of distorted rocksalt (NaCl)-type $\mathrm{SrO}$ interlayer with $\mathrm{SrTiO}_{3}$ as the $m=\infty$ member (Fig. 9a). RP phases exhibit a number of attractive properties such as superconductivity, dielectric characteristic, magnetoresistance, ionic conductivity, oxygen permeation, and catalysis, owing to their unique structural characteristics, which include the presence of perovskite block layers. $\mathrm{RP}$ phases can be regarded as a natural superlattice that has an intrinsic ability to exhibit low lattice thermal conductivity ( $\kappa_{\text {lattice }}$ ), due to the enhancement of phonon scattering at the numerous internal interfaces of $\mathrm{SrO}$ layers in these $\mathrm{SrO}\left(\mathrm{SrTiO}_{3}\right)_{m}$ compounds. Further, it was expected that RP compounds doped with $\mathrm{Nb}^{5+}$ at $\mathrm{Ti}^{4+}$ site $\left[\mathrm{SrO}\left(\mathrm{SrTi}_{1-x} \mathrm{Nb}_{x} \mathrm{O}_{3}\right)_{m}\right]$ or with trivalent rare-earth ions at $\mathrm{Sr}^{2+}$ sites $\left[\left(\mathrm{Sr}_{1-x} \mathrm{RE}_{x}\right)_{m+1} \mathrm{Ti}_{m} \mathrm{O}_{3 m+1}\right]$ may exhibit excellent transport properties due to the presence of the perovskite $\mathrm{SrTiO}_{3}$ blocks. The $Z T$ values of $\mathrm{Nb}-\mathrm{RP}$ and RE-RP increase with temperature and reach a maximum range of 0.1 to 0.24 at $1000 \mathrm{~K} .{ }^{18}$ However, the $Z T$ values are still low compared with conventional thermoelectric materials. One of the reasons for the low $Z T$ values of polycrystalline RP compounds may be the relatively low electrical conductivity originating from the random distribution of insulating $\mathrm{SrO}$ layers. Another reason is the low Seebeck coefficient, which originates from the small carrier effective mass $\left(m^{*}\right)$, being a property intrinsic to the material rather than to its polycrystalline nature. 
The Dion-Jacobson (DJ) phases are similar to RP phases but differ in that they contain A-site ordered cation and only one sheet of interslab A cations. Therefore, DJ phases do not support the phonon glass-electron crystal phenomenon of thermoelectric materials.

On the other hand, the Aurivillius phase consists of perovskite slabs of $\left(\mathrm{Bi}_{2} \mathrm{Ti}_{3} \mathrm{O}_{10}\right)^{2-}$ with $\left(\mathrm{Bi}_{2} \mathrm{O}_{2}\right)^{2+}$ sheets occupying the interslab regions (Fig. 9b). The perovskite-like slab is identical to that found in RP compounds. The $\left(\mathrm{Bi}_{2} \mathrm{O}_{2}\right)^{2+}$ sheets form a square planar net of oxygen atoms with $\mathrm{Bi}^{3+}$ occurring in an alternating sequence above and below the net, forming $\mathrm{BiO}_{4}$ square pyramids. Therefore, Aurivillius phase is also a representative of the phonon glass-electron crystal phenomenon. However, there are not many reports on the thermoelectric properties of Aurivillius phase. Recently, Kohri and Yagasaki ${ }^{96}$ reported a high Seebeck coefficient of $-28.3 \mathrm{mV} \mathrm{K}^{-1}$ at $1010 \mathrm{~K}$ for Aurivillius phase $\mathrm{Bi}_{2} \mathrm{VO}_{5.5}$, resulting in a dimensionless figure of merit of 0.06 at $910 \mathrm{~K}$. Therefore, layered perovskite oxides need to be explored extensively to obtain better oxide-based $n$-type thermoelectric materials.

\section{Layered Cobalt Oxides}

Layered transition-metal oxides exhibit very different but remarkable physical properties, as shown by the well-known high- $T_{\mathrm{c}}$ superconductivity of copper-based oxides, the colossal magnetoresistance in layered manganese oxides, and the room-temperature metal-insulator transition in thallium-based cobaltites. With the discovery of large thermopower in $\mathrm{Na}_{x} \mathrm{CoO}_{2}$ in 1997, layered cobalt oxides have been recognized as good candidates for thermoelectric power applications. ${ }^{5}$

$\mathrm{Na}_{x} \mathrm{CoO}_{2}$ has a hexagonal layered structure with alternating stacks of $\mathrm{CdI}_{2}$-type $\mathrm{CoO}_{2}$ layer and charge-balancing $\mathrm{Na}^{+}$ions along the $c$-axis. The
$\mathrm{CoO}_{2}$ layer is rhombohedrally distorted with edgesharing $\mathrm{CoO}_{6}$ octahedra stacked in alternating fashion (...ABC CBA...). This yields two different types of trigonal prismatic sites, which are partially occupied by $\mathrm{Na}^{+}$ions in a random way (Fig. 10a). In the layered structure, electrons and phonons follow different paths, enabling one to control the lattice thermal conductivity by properly choosing the number of insulating block layers. This is a manifestation of the electron crystal-phonon glass model, and this type of material design is termed "nanoblock integration." Therefore, the layered $\mathrm{Na}_{x} \mathrm{CoO}_{2}$ crystal structure can be regarded as a prototype phonon glass electronic crystal, where the ordered $\mathrm{CoO}_{2}$ layers serve as electronic transport layers, while the disordered $\mathrm{Na}^{+}$blocks serve as phonon-scattering regions to give low thermal conductivity. Further, the $\mathrm{CdI}_{2}$-type $\mathrm{CoO}_{2}$ blocks in layered cobalt oxides favor the low-spin state of $\mathrm{Co}^{3+}$ and $\mathrm{Co}^{4+}$, resulting in large thermopower at high temperatures. ${ }^{99,100}$

Recently, another class of cobaltite, called "modulated-layered" cobalt oxide or "misfit-layered" cobalt oxide, was discovered, in which the cobalt cations sit in a similar $\mathrm{CdI}_{2}$-type layer as in $\mathrm{Na}_{x} \mathrm{CoO}_{2}{ }^{101,102}$ $\mathrm{A}$ series of thallium and bismuth cobaltites, $\mathrm{Tl}_{\alpha}\left[(\mathrm{Sr}, \mathrm{Ca})_{1-\beta} \mathrm{O}\right]_{1+x} \mathrm{CoO}_{2}, \mathrm{Bi}_{\alpha}\left[\mathrm{A}_{0.75} \mathrm{Bi}_{0.25} \mathrm{O}\right]_{(3+3 x) / 2} \mathrm{CoO}_{2}$ $(\mathrm{A}=\mathrm{Ca}, \mathrm{Sr})$, and $\left[\mathrm{Bi}_{0.87} \mathrm{SrO}_{2}\right]_{2}\left[\mathrm{CoO}_{2}\right]_{1.82}$, represent the first oxides with a misfit-layered structure similar to that observed previously for chalcogenides. ${ }^{103}$ Among the misfit-layered cobalt oxides, $\mathrm{Ca}_{3} \mathrm{Co}_{4} \mathrm{O}_{9}$ and $\mathrm{Bi}_{2} \mathrm{M}_{2} \mathrm{Co}_{2} \mathrm{O}_{y}(\mathrm{M}=\mathrm{Ba}, \mathrm{Sr}, \mathrm{Ca})$ show interesting thermoelectric properties. The compounds $\mathrm{Ca}_{3} \mathrm{Co}_{4} \mathrm{O}_{9}$ and $\mathrm{Bi}_{2} \mathrm{M}_{2} \mathrm{Co}_{2} \mathrm{O}_{y}$ can be represented as $\left(\left[\mathrm{Ca}_{2} \mathrm{CoO}_{3}\right]^{\mathrm{RS}}\right.$ $\left.\left[\mathrm{CoO}_{2}\right]_{1.62}\right)$ and $\left(\left[\mathrm{Bi}_{0.87} \mathrm{MO}_{2}\right]_{2}^{\mathrm{RS}}\left[\mathrm{CoO}_{2}\right]_{1.82}\right)$, respectively, where RS refers to the block of rocksalt-type layers. Their structures also consist of a single $\mathrm{CdI}_{2^{-}}$ type $\mathrm{CoO}_{2}$ layer composed of $\mathrm{CoO}_{6}$ octahedra interleaved with rocksalt (RS)-type layers (Fig. 10b, c). However, unlike in $\mathrm{Na}_{x} \mathrm{CoO}_{2}$, each sublattice of $\mathrm{RS}$ (a)

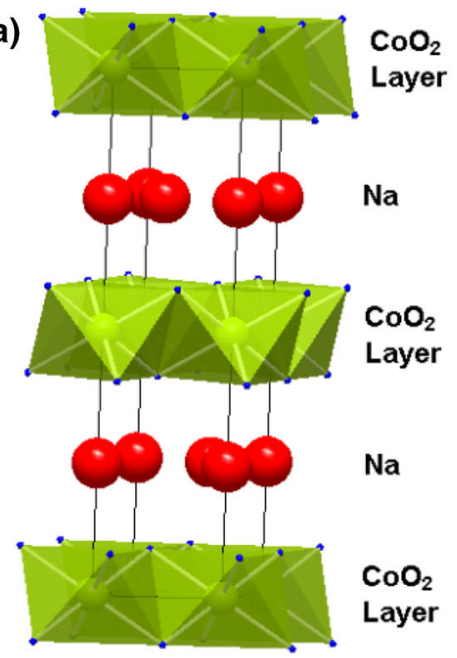

(b)
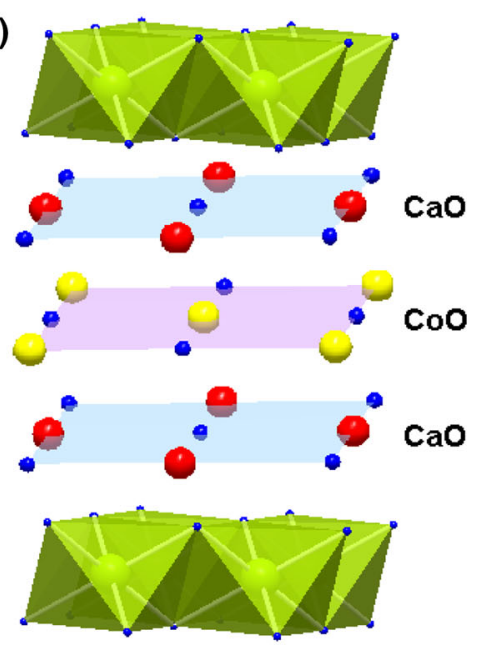

(c)

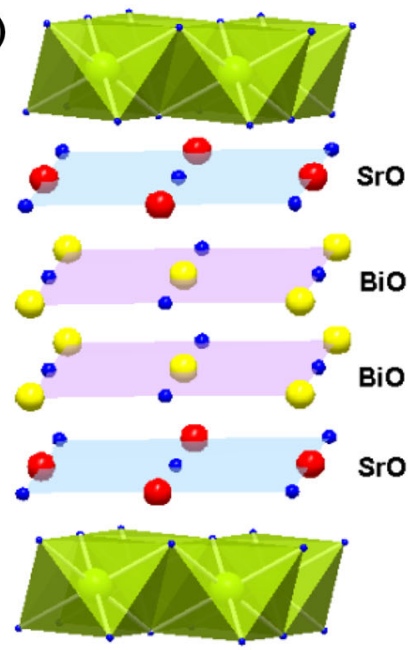

Fig. 10. Crystal structure of layered cobalt oxides (a) $\mathrm{Na}_{x} \mathrm{CoO}_{2}$, (b) $\mathrm{Ca}_{3} \mathrm{Co}_{4} \mathrm{O}_{9}$, and (c) $\mathrm{Bi}_{2} \mathrm{Sr}_{2} \mathrm{Co}_{2} \mathrm{O}_{y} \cdot{ }^{97,98}$ 
and $\mathrm{CoO}_{2}$ layers is incommensurate with respect to the other monoclinic $b$ lattice parameter. Electron diffraction patterns revealed the coexistence of two monoclinic subsystems of $\mathrm{CoO}_{2}$ layer and RS block with the same $a, c$, and $\beta$ parameters but different $b$ unit cell parameters, $b_{1}$ and $b_{2}$, with incommensurability ratio $b_{1} / b_{2}$. Similar to $\mathrm{Na}_{x} \mathrm{CoO}_{2}$, in the case of misfit-layered cobalt oxides, the $\mathrm{CoO}_{2}$ layer is responsible for electric conduction whereas the rocksalt block stabilizes the crystal structure through ionic interaction. Satake et al. ${ }^{104}$ showed that the rocksalt layer controls the lattice thermal conductivity; i.e., the in-plane thermal conductivity reduces with increasing rocksalt layers, leaving the electronic properties of the $\mathrm{CoO}_{2}$ blocks unperturbed. This indicates that tailoring the crystal structure by introducing more RS layers can eventually result in low thermal conductivity and thereby improve the thermoelectric properties. Such dependence of the thermoelectric properties on the crystal slabs has also been found in the case of $(\mathrm{ZnO})_{m} \operatorname{In}_{2} \mathrm{O}_{3}$ and Zintl compounds. ${ }^{45,105}$

$\mathrm{Na}_{x} \mathrm{CoO}_{2}$ single crystal shows large thermopower of $100 \mu \mathrm{V} \mathrm{K}^{-1}$ and low electrical resistivity of $200 \mu \Omega \mathrm{cm}$, resulting in a power factor of $50 \mu \mathrm{W} \mathrm{K} \mathrm{K}^{-2} \mathrm{~cm}^{-1}$ at $300 \mathrm{~K}$. The room-temperature thermal conductivity of single-crystal $\mathrm{Na}_{x} \mathrm{CoO}_{2}$ lies between $4 \mathrm{~W} \mathrm{~m}^{-1} \mathrm{~K}^{-1}$ and $5 \mathrm{~W} \mathrm{~m}^{-1} \mathrm{~K}^{-1}$ at $300 \mathrm{~K}^{20,106,107}$ The high-temperature properties of $\mathrm{Na}_{x} \mathrm{CoO}_{2}$ single crystal result in $Z T \approx 1$ at $800 \mathrm{~K}$. Polycrystalline $\mathrm{Na}_{x} \mathrm{CoO}_{2}$ has high resistivity resulting in a low $Z T$ value of $0.8 .^{108,109}$ However, application of $\mathrm{Na}_{x} \mathrm{CoO}_{2}$ as a high-temperature thermoelectric oxide is limited due to its hygroscopicity in air and the volatility of sodium above $800^{\circ} \mathrm{C}$, resulting in material instability.

The thermoelectric properties of misfit-layered oxide single crystals showed the largest $Z T$ of 1.2 to 2.7 for $\mathrm{Ca}_{3} \mathrm{Co}_{4} \mathrm{O}_{9}$ at $873 \mathrm{~K}$, and $Z T \geq 1.1$ for $\mathrm{Bi}_{2} \mathrm{Sr}_{2}$ $\mathrm{Co}_{2} \mathrm{O}_{9}$ at $1000 \mathrm{~K} .{ }^{110,111}$ However, strong anisotropy in the thermoelectric parameters and nonuniform crystal growth limit the performance of bulk compositions to a maximum $Z T$ of 0.5 on doping. ${ }^{112-115}$

\section{Layered Oxychalcogenides}

Recently, Li et al. ${ }^{116-120}$ reported the thermoelectric properties of $\mathrm{BiCuSeO}$, a quaternary oxychalcogenide of the $\mathrm{LnCuChO}$ system ( $\mathrm{Ln}$ : trivalent ions $\mathrm{La}$, $\mathrm{Bi}, \mathrm{Nd}$; Ch: chalcogenide ions such as $\mathrm{S}$, Se, Te) exhibiting high figure of merit as an oxide material reaching $Z T \approx 0.9$ at $900 \mathrm{~K}$. Quaternary oxychalcogenides ( $\mathrm{LnCuChO}$ ) belong to the $\mathrm{ZrSiCuAs}$ structure type in the tetragonal $P 4 / \mathrm{mmm}$ space group. The crystal structure comprises $\left(\mathrm{Cu}_{2} \mathrm{Ch}_{2}\right)^{2-}$ layers stacked alternately with $\left(\mathrm{Ln}_{2} \mathrm{O}_{2}\right)^{2+}$ layers along the $c$-axis of the tetragonal cell, giving rise to two-dimensional confinement effects based on the natural superlattice structure $^{116,121}$ (Fig. 11). The Seebeck coefficient is expected to be large due to the carrier confinement effect along the $c$-axis. ${ }^{54}$ It is reported that the

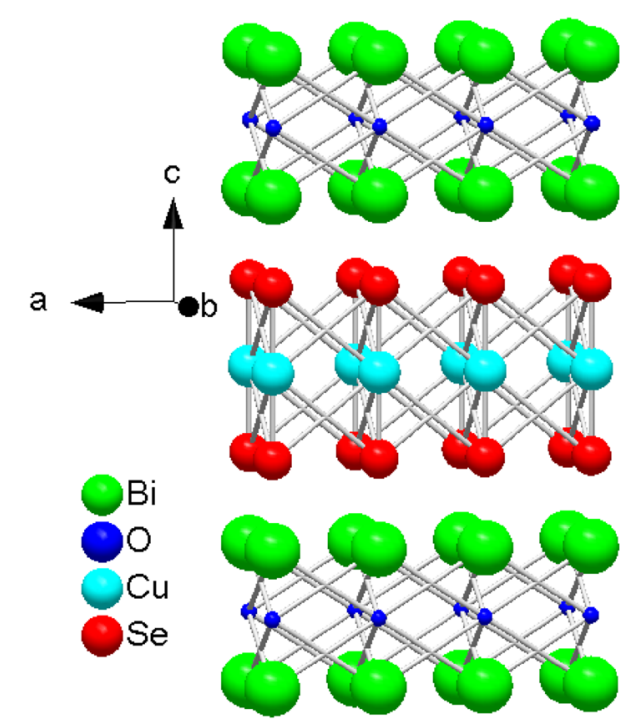

Fig. 11. Crystal structure of BiCuSeO with a layered ZrSiCuAs structure type with tetragonal $P 4 / \mathrm{nmm}$ space group.

$\left(\mathrm{Ln}_{2} \mathrm{O}_{2}\right)^{2+}$ layer acts as a blocking barrier for carrier transport, and the $\left(\mathrm{Cu}_{2} \mathrm{Ch}_{2}\right)^{2-}$ layer acts as a conductive layer due to the I-VI semiconductor nature arising from the tetrahedral $\mathrm{CuSe}_{4}$ or $\mathrm{CuS}_{4}$ structure, similar to those in III-V and II-VI semiconductors. ${ }^{122}$ Many of these LnChCuO oxychalcogenides exhibit $p$-type conductivities as high as $910 \mathrm{~S} / \mathrm{cm}$ with hole concentrations larger than $10^{21} \mathrm{~cm}^{-3}$ and hole mobilities as high as $3.5 \mathrm{~cm}^{2} \mathrm{~V}^{-1} \mathrm{~s}^{-1}$. Further, the layered crystal structure may also lead to low thermal conductivity by enhancing phonon scattering on the interfaces, the presence of heavy elements, and weak bonding between layers. ${ }^{41}$ The wide bandgap $(>3 \mathrm{eV})$ of $\mathrm{LnCuChO}$ compounds is primarily determined by the $\left(\mathrm{Cu}_{2} \mathrm{Ch}_{2}\right)^{2-}$ layers: the $\mathrm{Cu} 4 s$ orbitals mainly control the conduction-band minima (CBM), while admixed $\mathrm{Cu} 3 d$ and $\mathrm{Ch} p$ orbitals mainly control the valence-band maxima $(\mathrm{VBM}) .{ }^{121}$

Further, in the case of $\mathrm{BiCuSeO}$, the pseudoclosed-shell $6 s^{2}$ configuration of $\mathrm{Bi}^{3+}$ forms largely hybridized orbitals (i.e., hole transport paths) with the $p$ orbitals of the Se anion at the VBM compositions, resulting in high-mobility $p$-type conduction compared with other $\mathrm{LnCuOCh}$ oxychalcogenides. $\mathrm{BiCuSeO}$ is reported to show good electrical conductivity above $4 \times 10^{3} \mathrm{~S} \mathrm{~m}^{-1}$, large Seebeck coefficient above $200 \mu \mathrm{V} \mathrm{K}^{-1}$, and low thermal conductivity of $0.5 \mathrm{~W} \mathrm{~m}^{-1} \mathrm{~K}^{-1}$, resulting in a figure of merit of 0.7 at $773 \mathrm{~K}^{117}$ Further, a $Z T$ value of 1.1 at $923 \mathrm{~K}$ has been obtained for heavily doped $\mathrm{BiCuSeO}$ with the addition of $\mathrm{Ba}\left(\mathrm{Bi}_{1-x} \mathrm{Ba}_{x} \mathrm{CuSeO}\right)$. $\mathrm{Ba}$ doping of $\mathrm{BiCuSeO}$ changes the electrical transport property to metal-like behavior, resulting in a substantial increase of $Z T$. So far, this is the highest $Z T$ value reported for a $p$-type oxide thermoelectric material. ${ }^{120}$ 


\section{CONCLUSIONS}

The scarcity of fossil fuels and accompanying adverse environmental concerns demand alternative renewable energy sources. In light of this, thermoelectric energy conversion using thermoelectric materials has received more attention due to its simple configuration, low level of maintenance, ruggedness, and lack of moving parts. Heavily doped semimetals such as $\mathrm{Bi}_{2} \mathrm{Te}_{3^{-}}, \mathrm{PbTe}-$, and SiGe-based intermetallic alloys form the benchmark for commercial applications of thermoelectric power generation between $300 \mathrm{~K}$ and $800 \mathrm{~K}$. During the last decade, research on oxide thermoelectric materials has become extensive due to their structural and chemical stabilities, oxidation resistance, environmental friendliness, easy manufacturing, and low cost. Transition-metal oxides with strongly correlated electron systems are emerging as new thermoelectric materials with figure of merit $(Z T \approx 1)$ comparable to conventional materials. Through the crystal structure, the electron, spin, and orbital degeneracy, polaron hopping, and phonon scattering at interfaces, all three transport properties, viz. the thermopower, electrical conductivity, and thermal conductivity, can be manipulated.

Thermoelectric transition-metal oxides can be categorized into four different classes based on their crystal structure as (i) wide-bandgap semiconductor oxides, (ii) perovskite-based oxides, (iii) layered cobalt oxides, and (iv) layered oxychalcogenides. Although wide-bandgap semiconductor oxides such as $\mathrm{ZnO}, \mathrm{SnO}_{2}$, and $\mathrm{In}_{2} \mathrm{O}_{3}$ exhibit high power factors of $\sim 10^{-3} \mathrm{~W} \mathrm{~m}^{-1} \mathrm{~K}^{-2}$ to $10^{-4} \mathrm{~W} \mathrm{~m}{ }^{-1} \mathrm{~K}^{-2}$, their high thermal conductivity is an impediment to practical application as $n$-type thermoelectric materials. This high thermal conductivity is being addressed by in situ nanostructuring in doped $\mathrm{ZnO}$ and $\mathrm{In}_{2} \mathrm{O}_{3}$. Other wide-bandgap semiconductors with $p$-type conduction are the $\mathrm{BiCuSeO}$-based oxychalcogenides, which show figures of merit close to unity due to the two-dimensional confinement effect based on the natural superlattice structure consisting of conducting $\left(\mathrm{Cu}_{2} \mathrm{Se}_{2}\right)^{2-}$ layers stacked alternately with nonconducting $\left(\mathrm{Bi}_{2} \mathrm{O}_{2}\right)^{2+}$ layers along the $c$-axis. Layered cobalt oxides such as $\mathrm{Na}_{x} \mathrm{CoO}_{2}, \mathrm{Ca}_{3} \mathrm{Co}_{4} \mathrm{O}_{9}$, and $\mathrm{Bi}_{2} \mathrm{Sr}_{2} \mathrm{Co}_{2} \mathrm{O}_{y}$ with $p$-type conduction show figures of merit of $\sim 0.45$ for polycrystalline samples arising due to the phonon glass-electron crystal nature of their structure of alternating stacks of $\mathrm{CdI}_{2}$-type ordered $\mathrm{CoO}_{2}$ conducting layers and rocksalt-type disordered phonon-scattering layers. The simple perovskite-based oxides $\mathrm{SrTiO}_{3}$ and $\mathrm{CaMnO}_{3}$ are promising $n$-type candidates, achieving $Z T \approx 0.4$ due to their flexible crystal structure. Further studies have revealed that double perovskites with ordered-disordered structure would be potential candidates to explore as $n$-type oxide thermoelectric materials. Layered perovskites with Ruddlesden-Popper and Aurivillius structures need to be explored extensively to obtain better $n$-type oxide thermoelectric materials. Last but not least, efforts should be made towards exploring existing materials or identifying new materials that show both $n$ - and $p$-type conduction, possess the same crystal structure, and exhibit similar physical and chemical properties leading to high conversion efficiency of oxide-based thermoelectric generators.

\section{REFERENCES}

1. F.J. DiSalvo, Science 238, 703 (1999).

2. L.E. Bell, Science 321, 1457 (2008).

3. G.J. Snyder and E.S. Toberer, Nat. Mater. 7, 105 (2008).

4. T.M. Tritt, Semiconductors and Semimetals: Recent Trends in Thermoelectric Materials Research I \& II (San Diego: Academic, 2001).

5. D.M. Rowe, Thermoelectrics Handbook: Micro to Nano (Boca Raton: CRC Press, Taylor \& Francis Group, 2006).

6. B.I. Ismail and W.H. Ahmed, Recent Pat. Electr. Eng. 2, 27 (2009).

7. T.J. Seebeck, Abhand Deut. Akad. Wiss. Berlin 265 (1822).

8. E. Altenkirch, Phys. Z 12, 920 (1911).

9. G.S. Nolas, J. Sharp, and H.J. Goldsmid, Thermoelectrics, Basic Principles and New Materials Developments (Berlin: Springer, 2001).

10. G.J. Snyder, Electrochem. Soc. Interface 54 (2008).

11. A.F. Ioffe, Semiconductor Thermoelements and Thermoelectric Cooling (London: Infosearch Limited, 1957), p. 132.

12. B. Poudel, Q. Hao, Y. Ma, Y. Lan, A. Minnich, B. Yu, X. Yan, D. Wang, A. Muto, D. Vashaee, X. Chen, J. Liu, M.S. Dresselhaus, G. Chen, and Z. Ren, Science 320, 634 (2008).

13. J.P. Heremans, V. Jovovic, E.S. Toberer, A. Saramat, K. Kurosaki, A. Charoenphakdee, S. Yamanaka, and G.J. Snyder, Science 321, 554 (2008).

14. A.D. LaLonde, Y. Pei, H. Wang, and G.J. Snyder, Mater. Today 14, 526 (2011).

15. H. Ohta, K. Sugiura, and K. Koumoto, Inorg. Chem. 47, 8429 (2008).

16. J. He and Y. Liu, J. Mater. Res. 26, 1762 (2011).

17. M. Ohtaki, Newsletter Kyushu University G-COE program Novel Carbon Resources Sciences 3, 8 (2010).

18. K. Koumoto, Y.F. Wang, R. Zhang, A. Kosuga, and R. Funahashi, Annu. Rev. Mater. Res. 40, 363 (2010).

19. K. Koumoto, I. Terasaki, and R. Funahashi, MRS Bull. 31, 206 (2006)

20. I. Terasaki, Y. Sasago, and K. Uchinokura, Phys. Rev. B 56, R12685 (1997).

21. C. Goupil, Thermodyn. Thermoelectr. Thermodyn., ed. M. Tadashi (2011). ISBN:978-953-307-544-0, InTech, doi: 10.5772/12988. Available from: http://www.intechopen.com/ download/get/type/pdfs/id/13251.

22. C. Goupil, W. Seifert, K. Zabrocki, E. Müller, and G.J. Snyder, Entropy 13, 1481 (2011).

23. P.M. Chaikin and G. Beni, Phys. Rev. B 13, 647 (1976).

24. W. Koshibae, K. Tsutsui, and S. Maekawa, Phys. Rev. B Condens. Matter 62, 6869 (2000).

25. N. Tsuda, K. Nasu, A. Fujimori, and K. Siratori, Electronic Conduction in Oxides, 2nd ed. (Berlin: Springer, 2000).

26. N.F. Mott and E.A. Davis, Electronic Processes in Noncrystalline Materials (Oxford: Clarendon, 1971).

27. G.N. Austin and N.F. Mott, Adv. Phys. 18, 41 (1969).

28. A. Miller and E. Abrahams, Phys. Rev. 120, 745 (1960).

29. N.F. Mott, J. Non-Cryst. Solids 1, 1 (1968).

30. J. Schnakenberg, Phys. Status Solidi 28, 623 (1968).

31. E.S. Toberer, A. Zevalkink, and G.J. Snyder, J. Mater. Chem. 21, 15843 (2011).

32. M.D. Dresselhaus, G. Chen, M.Y. Tang, R. Yang, H. Lee, D. Wang, Z. Ren, and J.-P. Fleurial, Adv. Mater. 19, 1043 (2007)

33. M.G. Kanatzidis, Chem. Mater. 22, 648 (2010).

34. M. Ohtaki, T. Tsubota, K. Eguchi, and H. Arai, J. Appl. Phys. 79, 1816 (1996).

35. T. Tsubota, M. Ohtaki, K. Eguchi, and H. Arai, J. Mater. Chem. 7, 85 (1997). 
36. T. Tsubota, M. Ohtaki, K. Eguchi, and H. Arai, J. Mater. Chem. 8, 409 (1998).

37. M. Ohtaki, K. Araki, and K. Yamamoto, J. Electron. Mater. 38,1234 (2009).

38. D.F. Morgan and D.A. Wright, J. Appl. Phys. 17, 337 (1966).

39. T. Tsubota, T. Ohno, N. Shiraishi, and Y. Miyazaki, J. Alloys Compd. 463, 288 (2008).

40. S. Yanagiya, N.V. Nong, J. Xu, M. Sonne, and N. Pryds, J. Electron. Mater. 40, 674 (2011).

41. D. Berardan, E. Guilmeau, A. Maignan, and B. Raveau, Solid State Commun. 146, 97 (2008).

42. M. Ohtaki and R. Hayashi, Proceedings of the 25th International Conference on Thermoelectrics (ICT 2006) (Piscataway: IEEE, 2006), pp. 276-279.

43. M. Ohtaki, R. Hayashi, and K. Araki, Proceedings of the 26th International Conference on Thermoelectrics (ICT 2007) (Piscataway: IEEE, 2008), p. 112.

44. P. Jood, R.J. Mehta, Y. Zhang, G. Peleckis, X. Wang, R.W. Siegel, T.B. Tasciuc, S.X. Dou, and G. Ramanath, Nano Lett. 11, 4337 (2011).

45. H. Ohta, W.-S. Seo, and K. Koumoto, J. Am. Ceram. Soc. 79, 2193 (1996).

46. R.H. Mitchell, Perovskites-Modern and Ancient (Thunder Bay, ON: Almez, 2002)

47. R.M. Tiwari, M. Gadhvi, A. Nag, N.Y. Vasanthacharya, and J. Gopalakrishnan, J. Chem. Sci. 122, 529 (2010).

48. R. Robert, L. Bocher, M. Trottmann, A. Reller, and A. Weidenkaff, J. Solid State Chem. 179, 3893 (2006).

49. R. Robert, L. Bocher, B. Sipos, M. Döbeli, and A. Weidenkaff, Prog. Solid State Chem. 35, 447 (2007).

50. R. Robert, M.H. Aguirre, P. Hug, A. Reller, and A. Weidenkaff, Acta Mater. 55, 4965 (2007).

51. A.J. Zhou, T.J. Zhu, and X.B. Zhao, J. Mater. Sci. 43, 1520 (2008).

52. T. Okuda, K. Nakanishi, S. Miyasaka, and Y. Tokura, Phys. Rev. B 63, 113104 (2001).

53. S. Ohta, T. Nomura, H. Ohta, and K. Koumoto, J. Appl. Phys. 97, 0341061 (2005).

54. H. Ohta, S. Kim, Y. Mune, T. Mizoguchi, K. Nomura, S. Ohta, T. Nomura, Y. Nakanishi, Y. Ikuhara, M. Hirano, H. Hosono, and K. Koumoto, Nat. Mater. 6, 129 (2007).

55. H. Ohta, Y. Mune, K. Koumoto, T. Mizoguchi, and Y. Ikuhara, Thin Solid Films 516, 5916 (2008).

56. H. Ohta, Phys. Status Solidi B 245, 2363 (2008).

57. R. Moos, A. Gnudi, and K.H. Hardtl, J. Appl. Phys. 78, 5042 (1995).

58. H. Muta, K. Kurosaki, and S. Yamanaka, J. Alloys Compd. 350,292 (2003).

59. H. Muta, K. Kurosaki, and S. Yamanaka, J. Alloys Compd. 392, 306 (2005).

60. S. Ohta, T. Nomura, H. Ohta, H. Hosono, and K. Koumoto, Appl. Phys. Lett. 87, 092108 (2005).

61. H.C. Wang, C.L. Wang, W.B. Su, J. Liu, Y. Zhao, H. Peng, J.L. Zhang, M.L. Zhao, J.C. Li, N. Yin, and L.M. Mei, J. Alloys Compd. 486, 693 (2009).

62. H.C. Wang, C.L. Wang, W.B. Su, J. Liu, Y. Zhao, H. Peng, J.L. Zhang, M.L. Zhao, J.C. Li, N. Yin, and L.M. Mei, Mater. Res. Bull. 45, 809 (2010).

63. H.C. Wang, C.L. Wang, W.B. Su, J. Liu, Y. Sun, H. Peng, and L.M. Mei, J. Am. Ceram. Soc. 94, 838 (2011).

64. D.B. Marsh and P.E. Parris, Phys. Rev. B 54, 16602 (1996)

65. B.T. Cong, T. Tsuji, P.X. Thao, P.Q. Thanh, and Y. Yamamura, Phys. B 352, 18 (2004).

66. D. Flahaut, T. Mihara, R. Funahashi, N. Nabeshima, K Lee, H. Ohta, and K. Koumoto, J. Appl. Phys. 100, 084911 (2006).

67. Y. Wang, Y. Sui, and W. Su, J. Appl. Phys. 104, 093703 (2008).

68. A. Kosuga, Y. Isse, Y. Wang, K. Koumoto, and R. Funahashi, J. Appl. Phys. 105, 931717 (2009).

69. J. Lan, Y. Lin, A. Mei, C. Nan, Y. Liu, and B. Zhang, J. Mater. Sci. Technol. 25, 535 (2009).

70. Y. Wang, Y. Sui, H. Fan, X. Wang, Y. Su, W. Su, and X. Liu, Chem. Mater. 21, 4653 (2009).
71. J. Lan, Y.H. Lin, H. Fang, A. Mei, C.W. Nan, Y. Liu, S. Xu, and M. Petersz, J. Am. Ceram. Soc. 93, 2121 (2010).

72. Y. Wang, Y. Sui, X. Wang, and W. Su, Appl. Phys. Lett. 97, 052109 (2010).

73. H. Taguchi, T. Kugi, M. Kato, and K. Hirota, J. Am. Ceram. Soc. 93, 3009 (2010).

74. C.J. Liu, A. Bhaskar, and J.J. Yuan, Appl. Phys. Lett. 96, 214101 (2011).

75. S.M. Choi, C.H. Lim, and W.S. Seo, J. Electron. Mater. 40, 551 (2011).

76. F. Kawashima, X.Y. Huang, K. Hayashi, Y. Miyazaki, and T. Kajitani, J. Electron. Mater. 38, 1159 (2009).

77. G. Xu, R. Funahashi, Q. Pu, B. Liu, R. Tao, and G. Wang, Solid State Ion. 172, 147 (2004).

78. L. Bocher, M.H. Aguirre, D. Logvinovich, A. Shkabko, R. Robert, M. Trottmann, and A. Weidenkaff, Inorg. Chem. 47, 8077 (2008).

79. J.W. Park, D.H. Kwak, S.H. Yoon, and S.C. Choi, J. Alloys Compd. 487, 550 (2009).

80. X.Y. Huang, Y. Miyazaki, and T. Kajitani, Solid State Commun. 145, 132 (2008).

81. A. Maignan, C. Martin, C. Autret, M. Hervieu, B. Raveaua, and J. Hejtmanek, J. Mater. Chem. 12, 1806 (2002).

82. T. Okuda and Y. Fujii, J. Appl. Phys. 108, 103702 (2010).

83. S. Urata, R. Funahashi, T. Mihara, A. Kosuga, S. Sodeoka, and T. Tanaka, Int. J. Appl. Ceram. Technol. 4, 535 (2007).

84. A. Nag, F. D'Sa, and V. Shubha, Mater. Chem. Phys. (to be communicated).

85. A. Nag, F. D'Sa, and V. Shubha, Mater. Lett. (to be communicated).

86. A. Nag, J. Manjanna, R.M. Tiwari, and J. Gopalakrishnan, Chem. Mater. 20, 4420 (2008).

87. K.-I. Kobayashi, T. Kimura, H. Sawada, K. Terakura, and Y. Tokura, Nature 395, 677 (1998).

88. N.S. Rogado, J. Li, A.W. Sleight, and M.A. Subramanian, Adv. Mater. 17, 2225 (2005).

89. R.J. Booth, R. Fillman, H. Whitaker, A. Nag, R.M. Tiwari, K.V. Ramanujachary, J. Gopalakrishnan, and S.E. Lofland, Mater. Res. Bull. 44, 1559 (2009).

90. M. Azuma, K. Takata, T. Saito, S. Ishiwata, Y. Shimakawa, and M. Takano, J. Am. Chem. Soc. 127, 8889 (2005)

91. C. Felser, G.H. Fecher, and B. Balke, Angew. Chem. Int. Ed. 46,668 (2007).

92. T. Sugaharaa, N.V. Nongb, and M. Ohtakic, Mater. Chem. Phys. 133, 630 (2012).

93. T. Sugahara, M. Ohtaki, and T. Souma, J. Ceram. Soc. Jpn. 116, 1278 (2008).

94. T. Sugahara and M. Ohtaki, Appl. Phys. Lett. 99, 062107 (2011).

95. R. Takahashi, R. Okazaki, Y. Yasui, I. Terasaki, T. Sudayama, H. Nakao, Y. Yamasaki, J. Okamoto, Y. Murakami, and Y. Kitajima, J. Appl. Phys. Lett. 112, 073714 (2012)

96. H. Kohri and T. Yagasaki, Adv. Sci. Technol. 77, 285 (2013).

97. Y. Miyazaki, Solid State Ion. 172, 463 (2004).

98. H. Muguerra, D. Grebille, E. Guilmeau, and R. Cloots, Inorg. Chem. 47, 2464 (2008).

99. W. Koshibae, K. Tsutsui, and S. Maekawa, Phys. Rev. B 62, $6869(2000)$

100. Y. Wang, N.S. Rogado, R.J. Cava, and N.P. Ong, Nature 423, 425 (2003).

101. J.-M. Tarascon, R. Ramesh, P. Barboux, M.S. Hedge, G.W. Hull, L.H. Greene, M. Giroud, Y. LePage, W.R. McKinnon, J.V. Waszcak, and L.F. Schneemeyer, Solid State Commun. 71, 663 (1989).

102. H. Leligny, D. Grebille, O. Pérez, A.C. Masset, M. Hervieu, and B. Raveau, Acta Cryst. B 56, 173 (2000).

103. A.C. Masset, C. Michel, A. Maiguan, M. Herivieu, O. Toulemonde, F. Studer, and B. Raveau, Phys. Rev. B 62, 166 (2000).

104. A. Satake, H. Tanaka, and T. Onkawa, J. Appl. Phys. 93, 931 (2004).

105. E.S. Toberer, A.F. May, and G.J. Snyder, Chem. Mater. 22, 624 (2010)

106. J. Molenda, C. Delmas, and P. Hagenmuller, Solid State Ion. 9 \& 10, 431 (1983). 
107. T. Tanaka, S. Nakamura, and S. Lida, Jpn. J. Appl. Phys. 33, L581 (1994).

108. K. Fujita, T. Mochida, and K. Nakamura, Jpn. J. Appl. Phys. 40, 4644 (2001).

109. M. Ito, T. Nagira, D. Furumoto, S. Katsuyama, and H. Nagai, Scr. Mater. 48, 403 (2003).

110. R. Funahashi, I. Matsubara, H. Ikuta, T. Takeuchi, U. Mizutani, and S. Sodeoka, Jpn. J. Appl. Phys. 40, 4644 (2001).

111. R. Funahashi and M. Shikano, Appl. Phys. Lett. 81, 1459 (2002).

112. S. Li, R. Funahashi, I. Matsubara, K. Ueno, S. Sodeoka, and H. Yamada, Chem. Mater. 12, 2424 (2000).

113. Y. Wang, Y. Sui, J. Cheng, X. Wang, and W. Su, J. Alloys Compd. 477, 817 (2009).

114. N.V. Nong, N. Pryds, S. Linderoth, and M. Ohtaki, Adv. Mater. 23, 2484 (2011).

115. N.V. Nong, S. Yanagiya, S. Monica, N. Pryds, and M. Ohtaki, J. Electron. Mater. 40, 716 (2011).
116. L.D. Zhao, D. Berardan, Y.L. Pei, C. Byl, L. Pinsard-Gaudart, and N. Dragoe, Appl. Phys. Lett. 97, 092118 (2010).

117. Y. Liu, L.D. Zhao, Y.C. Liu, J.L. Lan, W. Xu, F. Li, B.P. Zhang, D. Berardan, N. Dragoe, Y.H. Lin, C.W. Nan, J.F. Li, and H.M. Zhu, J. Am. Chem. Soc. 133, 20112 (2011).

118. D. Berardan, L.D. Zhao, C. Barreteau, and N. Dragoe, Phys. Status Solidi A 209, 2273 (2012).

119. F. Li, J.F. Li, L.D. Zhao, K. Xiang, Y. Liu, B.P. Zhang, Y.H. Lin, C.W. Nan, and H.M. Zhu, Energy Environ. Sci. 5, 7188 (2012).

120. J. Li, J.H. Sui, Y. Pei, C. Barreteau, D. Berardan, N. Dragoe, W. Cai, J. He, and L.D. Zhao, Energy Environ. Sci. 5, 8543 (2012).

121. H. Hiramatsu, H. Yanagi, T. Kamiya, K. Ueda, M. Hirano, and H. Hosono, Chem. Mater. 20, 326 (2008).

122. K. Ueda, H. Hiramatsu, H. Ohta, M. Hirano, T. Kamiya, and H. Hosono, Phys. Rev. B Condens. Matter Mater. Phys. 69, 155305 (2004). 